\title{
Structural similitude design for a scaled composite wing box based on optimised stacking sequence
}

C. You*, M. Yasaee, I. Dayyani

School of Aerospace, Transport and Manufacturing, Cranfield University, Cranfield, UK

\begin{abstract}
Testing appropriately-designed scaled-down structures instead of the full-size prototype structure is beneficial for quickly understanding the prototype structural behaviour in a cost-effective way. In this study, a novel approach is proposed to design scaled composite structures that can be used to predict the structural responses (e.g. static bending, modal behaviour, and compressive buckling) of the prototype. The objective is to overcome the main drawback of the conventional design method, which tends to result in low accuracy of the prototype prediction when certain variables cannot be appropriately scaled due to manufacturing constraints (e.g. ply thickness). In the present work, a set of scaling laws being independent of boundary conditions were firstly derived for plates and beams respectively based on their governing equations. The genetic algorithm (GA) was then applied to help design the stacking sequence of the scaled models, accommodating the mismatch in similarity conditions resulting from the manufacturing constraint in ply thickness. This GA-based design method was demonstrated to be effective in designing scaled plate, I-beam, and stiffened plate models, with improved accuracy in predicting the prototype structural behaviour compared with the conventional method. The application of this new design method was also extended to an A320 size wing box structure, validating its robustness for complex structures.
\end{abstract}

Keywords: Structural similitude; Genetic algorithm; Scaling laws; Wing box; Composite structure

\section{Introduction}

\subsection{Similitude theory}

The design and certification of large-scale complex structures (such as the wing of civil aircraft) has always been a challenging task. One of the main difficulties is that manufacturing and testing a full-scale prototype structure is not always possible at the design stage. Even when it is possible, the associated process tends to be high-cost and time-consuming. These barriers impede the validation of the reliability of the design. To overcome this obstacle, many researchers investigated the possibility of designing and testing scaled-down models which could effectively represent the working condition of the full-scale prototype structure [1-4]. The relation between the scaled and prototype structures is referred to as structural similarity. This technique has been widely known as structural similitude design and analysis, which has the potential to allow studying and validating the large-scale complex structure in a more efficient way.

In order to ensure sufficient structural similarity between the scaled-down model and the prototype, structural similitude design needs to follow necessary similarity conditions, which describe the mathematical relationship

\footnotetext{
* Corresponding author.

Email address: c.you@cranfield.ac.uk (C. You)
} 
in structural variables (e.g. dimensions, loading magnitudes, material properties, etc.) between the scaled and the prototype structures. The scaling laws can be subsequently extracted from these similarity conditions and be used to extrapolate the experimental data of the scaled model to predict the structural behaviour of the prototype.

Dimensional analysis and the governing equation method are the two approaches that have been most widely applied to obtain the similarity conditions for a scaling task. Dimensional analysis has been in active use in various fields for over a century [5]. It is based on the famous Buckingham's $\pi$-theorem and requires all key variables of the investigated structural system to be listed with their units [6]. Each unit needs to be interpreted using basic dimensions such as length, time, mass, etc. It then results in a set of equations expressing different $\pi$-factors, which are in terms of non-dimensional products of the listed key variables of the structural system, from which the similarity conditions can be derived. This method does not require any knowledge regarding the mathematical relations between the involved variables, hence is advantageous to the system whose mathematical descriptions are yet known. However, the selection of key variables and basic dimensions is usually based on intuition and experience. Improper choices made by inexperienced users is likely to complicate or even fail the similitude analysis [1, 7]. By contrast, the governing equation method, which has not been widely applied until 1990s [8], is a more convenient scaling approach if the mathematical model (i.e. the governing equations) of the structural system is available. The similarity conditions, which are established by directly applying the similitude theory to the governing equations, are usually more specific than those obtained from dimensional analysis [2]. A comprehensive review summarising the up-do-date development of both the dimensional analysis and the governing equation method was presented by Coutinho et al. [9], which covers the application of both approaches in a wide range of aspects.

A scaled model is regarded as having complete similarity with respect to its full-scale prototype if all the similarity conditions are satisfied simultaneously. Nevertheless, complete similarity is sometimes difficult to achieve when designing a scaled model, owing to manufacturing restrictions in certain variables which cannot be appropriately scaled according to the similarity conditions [2, 10-14]. This situation is referred to as 'distortion' in the associated variables, and the resultant scaled models are regarded as 'distorted' models. Under such circumstances, the relation between the scaled and the prototype structures is termed partial similarity, which has been one of the main concerns in structural similitude design since it may lead to inaccurate prototype predictions [2, 10-14].

\subsection{Structural similarity for composite structures}

Structural similarity for structures made of isotropic materials (such as metals) has been extensively investigated at different complexity levels from simple components (e.g. beams, plates and shells) $[11,12,15,16]$ to complex structures [1, 14, 17-19]. By contrast, the studies on composite structures are still relatively scarce.

Simitses, Rezaeepazhand and Starnes [20-23] carried out a series of structural similitude analysis in designing and testing scaled-down angle-ply and cross-ply laminated plates for predicting the structural behaviour of the 
prototype. Displacements under static loading, critical buckling loads and modal frequencies were considered in their work. To obtain the similarity conditions and the scaling laws, the governing equation method was applied to the exact solution of the differential equations for plates based on specified boundary conditions (BCs). Ungbhakorn et al. [24, 25] extended their work by applying the governing equation method directly to the differential equations instead of to their solutions. This modification resulted in more generic scaling laws for angle-ply and cross-ply laminated plates, which were independent of the applied BCs.

According to the results reported in [20-25], complete similarity always leads to accurate prototype predictions. However, partial similarity, which occurs when the ply thickness cannot be scaled, tends to degrade the prediction accuracy of the prototype, particularly when the ply number in the scaled model is much less than that in the prototype. The method applied by them to design the distorted scaled models is termed the conventional partial similitude design method in the current study, which maintains the prototype stacking pattern but reduces its repeating times in the stacking sequence to accommodate the scaling distortion in ply thickness. Fig. 1(a)-(c), which takes a quasi-isotropic laminated prototype as an example, illustrates the difference between the stacking sequences resulting from complete and partial similitude designs following the methods applied in [20-25].

Considering the fact that encountering the problem associated with manufacturing constraint in ply thickness is very likely for a scaling task, improving the prediction accuracy of the prototype with existing scaling distortion in ply thickness is expected to be particularly beneficial to promote the feasibility of structural similitude design for composite structures. Asl et al. [26] attempted to achieve this by designing a scaled-down laminated I-beam which represented a utility-scale wind turbine rotor blade. The similarity conditions were obtained from the closed-form solution to the differential equations derived from the Timoshenko beam theory, assuming simply supported BCs. The main idea was to list all the possible stacking sequences considering the constraints in ply thickness and orientations, and then to select the one that best matched the similarity conditions in flexural and shear stiffness [27]. This method has been demonstrated to work well in predicting the displacement and strain distribution under static bending as well as the modal frequencies of the prototype. It seems promising to extend its application to laminated plates and shells. In addition, Torkamani et al. [14] attempted to overcome the difficulties in fabricating small-scale stiffeners when designing a scaled-down orthogonally stiffened cylindrical shell for vibration tests. Approaches such as changing the number of stiffeners and defining equivalent manufacturable stiffener cross sections were investigated numerically and experimentally to accommodate the geometric distortion. Although isotropic material was applied in this study, it indeed implies a promising direction of partial similitude design of composite structures given the good designability of composites - some features of the scaled model could be re-designed to be different from the prototype to promote structural similarity. 


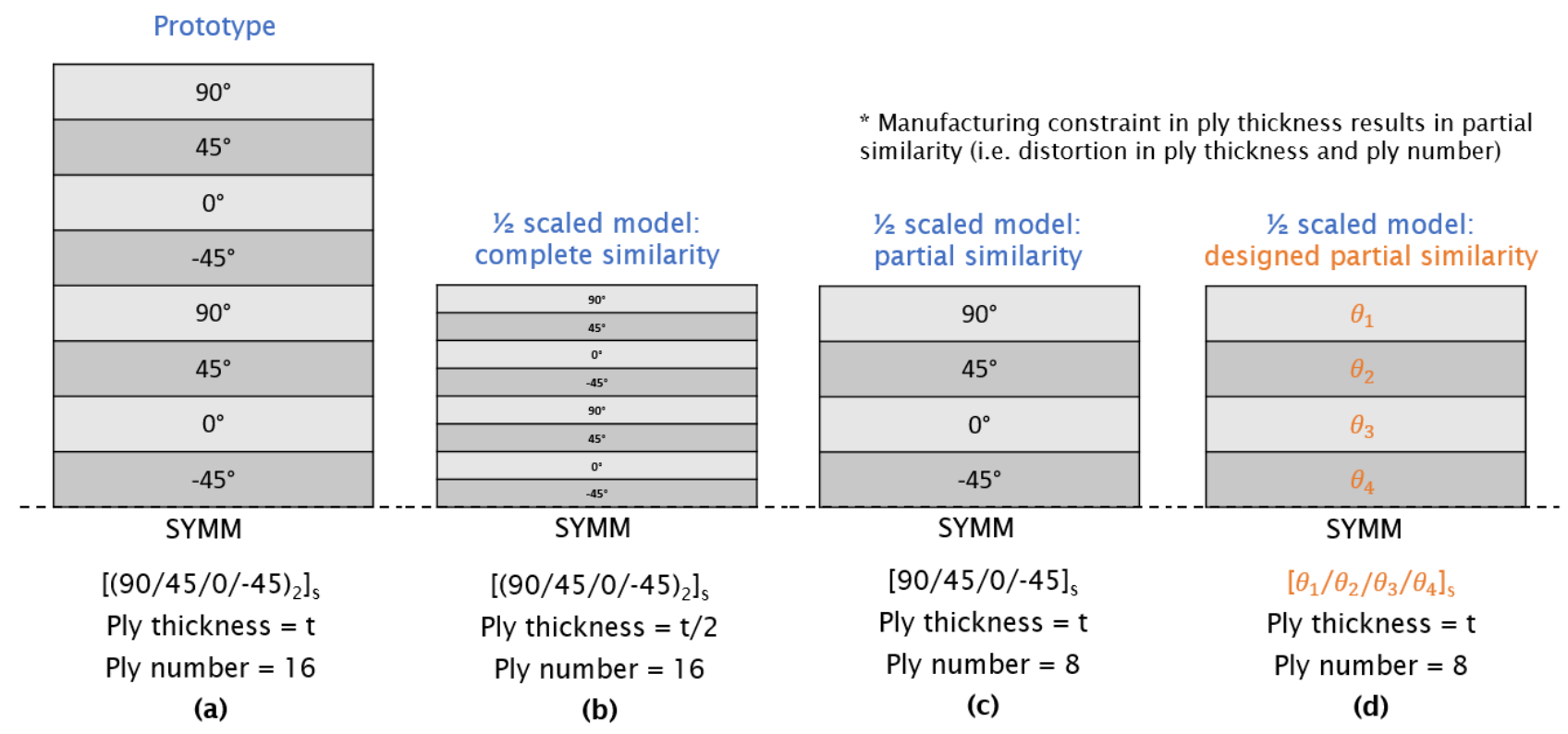

Fig. 1. Illustration of the difference in stacking sequence between a quasi-isotropic laminated prototype and its $1 / 2$ scaled models designed following different similitude design methods: (a) the prototype, (b) complete similarity, (c) partial similarity (conventional partial similitude design, CPSD) and (d) designed partial similarity (GA-based partial similitude design, GAPSD).

It is noteworthy that most of the published work with respect to composite structural similitude design remains at the component level (i.e. beams, plates, and shells). Fewer investigations focusing at the structural level have been reported. The main obstacle is that the mathematical model for the whole structural system is not always available, which impedes the application of the governing equation method. Hilburger et al. [13] investigated a built-up, multi-cell noncircular composite structure representing a portion of a blended-wing-body aircraft. Structural similitude design was carried out for each component separately by obtaining their similitude conditions from the differential equations for plates (based on the first-order shear-deformation plate theory). The sandwich construction in the prototype was replaced with a monolithic-laminate construction in scaled models for studying partial similarity. The displacement response of the prototype structure resulting from the combined internal pressure and mechanical loads was predicted using a 1/12 scaled model, which was assembled by joining the individually-designed scaled components. The prediction results further confirmed the high sensitivity of the prediction accuracy to partial similarity at the structural level. Cristiano et al. [28] proposed a modular concept for structural similitude analysis when an explicit governing equation for the complete structure is not available. It is similar to the method applied by Hilburger et al. [13] but becomes more systematic. According to this concept, the structure is decomposed into separate components where structural similitude design can be carried out separately based on the governing equations for different modules such as material, stacking sequence, stress-strain relation, equations of motion, etc. Then by ensuing the consistency of the scaling parameters at the interface between adjacent components (e.g. the displacement at the interface), a similitude relation between the components can be built up, leading to structural level scaling laws. However, the applicability of this concept was only demonstrated using a stiffened plate with isotropic material. 


\subsection{Objectives of the present study}

According to the literatures, there is still a lack of investigations in structural similitude design for complex composite structures, particularly in how to improve the prediction accuracy of the prototype structural behaviour in the condition of partial similarity when manufacturing constraints exist. In the current work, a novel structural partial similitude design approach based on genetic algorithm (GA) is proposed to improve the design of scaled-down composite structures when the ply thickness cannot be scaled. Composite structures with varying structural complexities have been investigated, including a rectangular plate, an I-shape beam, a stiffened plate and a typical wing box structure of single-aisle civil aircrafts.

The governing equation method was applied to obtain the similarity conditions which support structural similitude in static bending, linear buckling and the modal behaviour simultaneously. To accommodate the partial similarity resulting from the distortion in ply thickness, the stacking sequence of the scaled model was re-designed using the GA (as illustrated in Fig. 1(d)). The advantages of this method in terms of the prediction accuracy and the range of applicability have been demonstrated by comparing it with the conventional partial similitude design method (as illustrated in Fig. 1(c)). For brevity, the conventional and the GA-based partial similitude design are abbreviated to CPSD and GAPSD respectively in the following sections of this paper.

\section{Scaling methodology}

\subsection{Prototype stiffened plate}

In this study, the prototype stiffened plate is composed of a symmetric laminated plate and seven I-shape stiffeners. The dimensions of the plate are: $l=1200 \mathrm{~mm}$ (length), $w=800 \mathrm{~mm}$ (width) and $h=32 \mathrm{~mm}$ (thickness). The stacking sequence of the plate is [(95/45/0/-45) 16$]_{\mathrm{s}}$ with the ply thickness of $0.25 \mathrm{~mm}$. The cross section dimensions of the prototype I-shape stiffener are provided in Fig. 2. The web and flanges (top and bottom) of the stiffener share the same stacking sequence of $\left[(0 / \pm 45 / 90)_{3}\right]_{\mathrm{s}}$ with the ply thickness of $0.25 \mathrm{~mm}$. Carbon fiber/epoxy composite IM7/8552 was chosen as the material in this study, and the key material properties are listed in Table 1.

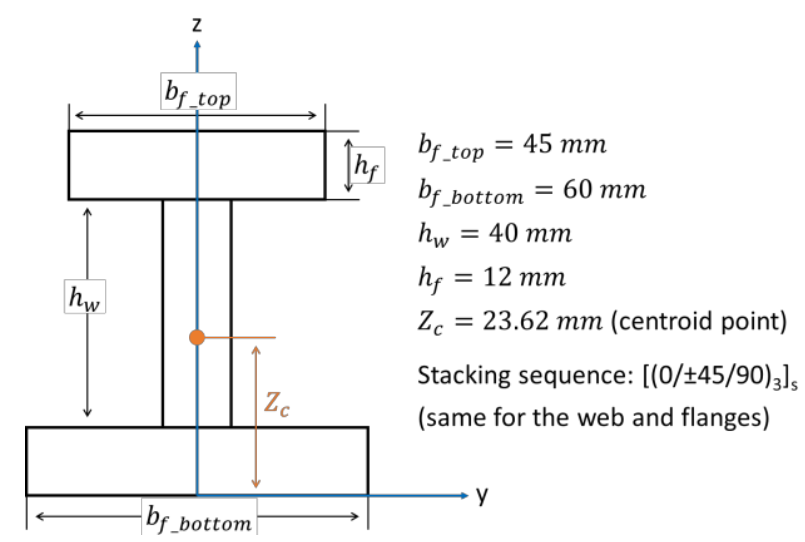

Fig. 2. Cross section dimensions of the prototype I-shape stiffener. 
Table 1. Key material properties of IM7/8552 [29].

\begin{tabular}{|l|l|l|l|l|l|l|l|l|l|}
\hline $\begin{array}{l}\text { E1 } \\
(\mathbf{G P a})\end{array}$ & $\begin{array}{l}\mathbf{E 2} \\
(\mathbf{G P a})\end{array}$ & $\begin{array}{l}\mathbf{E 3} \\
(\mathbf{G P a})\end{array}$ & $\mathbf{v 1 2}$ & $\mathbf{v 1 3}$ & $\mathbf{v 2 3}$ & $\begin{array}{l}\mathbf{G 1 2} \\
(\mathbf{G P a})\end{array}$ & $\begin{array}{l}\mathbf{G 1 3} \\
(\mathbf{G P a})\end{array}$ & $\begin{array}{l}\mathbf{G 2 3} \\
(\mathbf{G P a})\end{array}$ & $\boldsymbol{\rho}\left(\mathbf{g} / \mathbf{c m}^{\mathbf{3}}\right)$ \\
\hline 161.0 & 11.38 & 11.38 & 0.32 & 0.32 & 0.45 & 5.17 & 5.17 & 3.92 & 1.57 \\
\hline
\end{tabular}

The prototype stiffened plate model was developed using ABAQUS 6.14 by assembling the plate and I-beam models as illustrated in Fig. 3. Relative motion between the plate and the bottom flanges of the stiffeners has been prevented by ensuring consistent displacement at their interface using multi-point constraints (MPC). In ABAQUS, this was realised by using the surface-based tie constraints.

(a) $\times$

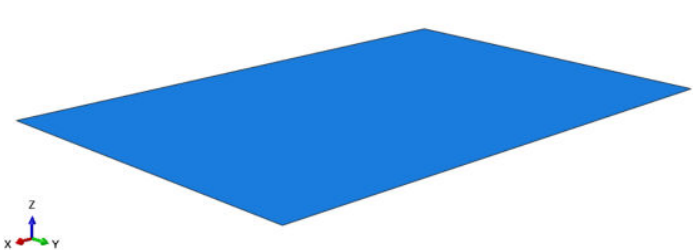

(b) $\times \overbrace{}^{2}$
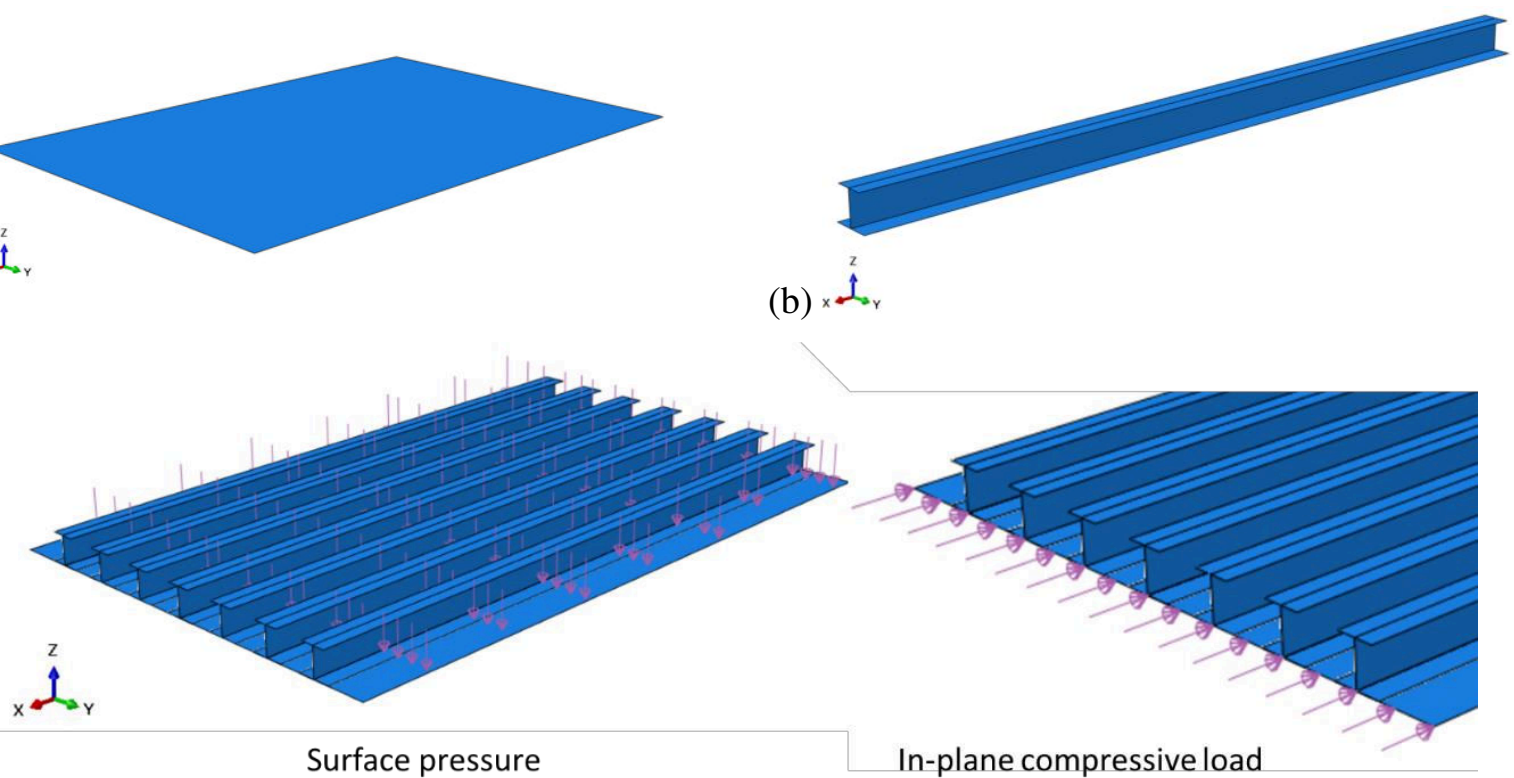

(c)

Fig. 3. (a) Plate, (b) stiffener and (c) stiffened plate model with illustration of the applied loading conditions.

To develop scaling laws for the stiffened plate, structural similitude analysis was firstly implemented to the plate and I-beam separately before they were assembled. In order to validate the applicability of the scaling method (to be proposed in Section 3) to various BCs, both clamped and simply supported models were considered. Surface pressure and in-plane compressive loads were also defined in the model to investigate various structural responses, as schematically shown in Fig. 3(c).

\subsection{Complete similarity and scaling laws}

Complete similarity conditions and the resultant scaling laws were firstly generated for the plate and I-beam respectively based on their differential governing equations. More generic scaling laws, which apply to the stiffened plate, were then obtained by satisfying the structural continuity condition. The material applied to the scaled models were assumed to be identical with the prototype. 


\subsubsection{Plate}

The differential equations governing the motion of symmetric laminated plates can be derived using the dynamic version of the principle of virtual displacements, based on the classical laminated plate theory (CLPT), which is an extension of the classical plate theory to composite laminates [30]. In CLPT, it is assumed that the Kirchhoff hypothesis holds. The obtained differential governing equations are:

$$
\begin{aligned}
& A_{11} \frac{\partial^{2} u_{0}}{\partial x^{2}}+2 A_{16} \frac{\partial^{2} u_{0}}{\partial x \partial y}+A_{66} \frac{\partial^{2} u_{0}}{\partial y^{2}}+A_{16} \frac{\partial^{2} v_{0}}{\partial x^{2}}+\left(A_{12}+A_{66}\right) \frac{\partial^{2} v_{0}}{\partial x \partial y}+A_{26} \frac{\partial^{2} v_{0}}{\partial y^{2}} \\
& =I_{0} \ddot{u}_{0}-I_{1} \frac{\partial \ddot{w}_{0}}{\partial x} \\
& A_{16} \frac{\partial^{2} u_{0}}{\partial x^{2}}+\left(A_{12}+A_{66}\right) \frac{\partial^{2} u_{0}}{\partial x \partial y}+A_{26} \frac{\partial^{2} u_{0}}{\partial y^{2}}+A_{66} \frac{\partial^{2} v_{0}}{\partial x^{2}}+2 A_{26} \frac{\partial^{2} v_{0}}{\partial x \partial y}+A_{22} \frac{\partial^{2} v_{0}}{\partial y^{2}} \\
& =I_{0} \ddot{v}_{0}-I_{1} \frac{\partial \ddot{w}_{0}}{\partial y} \\
& -D_{11} \frac{\partial^{4} w_{0}}{\partial x^{4}}-4 D_{16} \frac{\partial^{4} w_{0}}{\partial x^{3} \partial y}-2\left(D_{12}+2 D_{66}\right) \frac{\partial^{4} w_{0}}{\partial x^{2} \partial y^{2}}-4 D_{26} \frac{\partial^{4} w_{0}}{\partial x \partial y^{3}}-D_{22} \frac{\partial^{4} w_{0}}{\partial y^{4}} \\
& +\bar{N}_{x x} \frac{\partial^{2} w_{0}}{\partial x^{2}}+2 \bar{N}_{x y} \frac{\partial^{2} w_{0}}{\partial x \partial y}+\bar{N}_{y y} \frac{\partial^{2} w_{0}}{\partial y^{2}}+p \\
& =I_{0} \ddot{w}_{0}+I_{1}\left(\frac{\partial \ddot{u}_{0}}{\partial x}+\frac{\partial \ddot{v}_{0}}{\partial y}\right)-I_{2}\left(\frac{\partial^{2} \ddot{w}_{0}}{\partial x^{2}}+\frac{\partial^{2} \ddot{w}_{0}}{\partial y^{2}}\right)
\end{aligned}
$$

where the dots denote the derivative with respect to time $t . u_{0}, v_{0}$ and $w_{0}$ are the displacements of a point on the mid plane along $x, y$ and $z$ directions respectively. $\bar{N}_{x x}, \bar{N}_{x y}$ and $\bar{N}_{y y}$ denote the applied edge forces. $p$ represents the applied lateral pressure. The element of $[A]$ and $[D]$ matrices for composite laminates, $A_{i j}$ and $D_{i j}$, are calculated using Eq. (4) $[31,32] ;[B]$ matrix is not considered here due to stacking symmetry. The inertial terms $I_{i}$ are computed using Eq. (5), where $\rho$ is the density of the material.

$$
\begin{gathered}
A_{i j}=\sum_{k=1}^{n}\left(\bar{Q}_{i j}\right)_{k}\left(z_{k}-z_{k-1}\right), \quad D_{i j}=\frac{1}{3} \sum_{k=1}^{n}\left(\bar{Q}_{i j}\right)_{k}\left(z_{k}{ }^{3}-z_{k-1}{ }^{3}\right) \\
I_{i}=\int_{-\frac{1}{2} h}^{\frac{1}{2} h} \rho z^{i} d z \quad(i=0,1 \text { and } 2)
\end{gathered}
$$

Eq. (6)-(8), which describe the similarity conditions, can be obtained from Eq. (1)-(3) by applying the governing equation method. Detailed procedures of implementing the governing equation method has been elaborated in [2] hence is not introduced here. In Eq. (6)-(8), the scale factor (SF) of a specific parameter is defined as

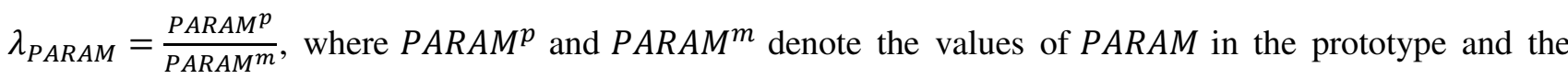
scaled model respectively. For example, the SF of the thickness of the plate $(h)$ is expressed as $\lambda_{h}=\frac{h^{p}}{h^{m}}$, and $\lambda_{h}=2$ denotes that the thickness of the prototype plate is scaled by half in the scaled model. 


$$
\begin{gathered}
\frac{\lambda_{A_{11}} \lambda_{u_{0}}}{\lambda_{x}{ }^{2}}=\frac{\lambda_{A_{66}} \lambda_{u_{0}}}{\lambda_{y}{ }^{2}}=\frac{\lambda_{A_{16}} \lambda_{v_{0}}}{\lambda_{x}{ }^{2}}=\frac{\lambda_{A_{26}} \lambda_{v_{0}}}{\lambda_{y}{ }^{2}}=\frac{\lambda_{A_{16}} \lambda_{u_{0}}}{\lambda_{x} \lambda_{y}}=\frac{\lambda_{A_{12}} \lambda_{v_{0}}}{\lambda_{x} \lambda_{y}}=\frac{\lambda_{A_{66}} \lambda_{v_{0}}}{\lambda_{x} \lambda_{y}}=\frac{\lambda_{I_{0}} \lambda_{u_{0}}}{\lambda_{t}{ }^{2}}=\frac{\lambda_{I_{1}} \lambda_{w_{0}}}{\lambda_{t}{ }^{2} \lambda_{x}} \\
\frac{\lambda_{A_{16}} \lambda_{u_{0}}}{\lambda_{x}{ }^{2}}=\frac{\lambda_{A_{26}} \lambda_{u_{0}}}{\lambda_{y}{ }^{2}}=\frac{\lambda_{A_{66}} \lambda_{v_{0}}}{\lambda_{x}{ }^{2}}=\frac{\lambda_{A_{22}} \lambda_{v_{0}}}{\lambda_{y}{ }^{2}}=\frac{\lambda_{A_{26}} \lambda_{v_{0}}}{\lambda_{x} \lambda_{y}}=\frac{\lambda_{A_{12}} \lambda_{u_{0}}}{\lambda_{x} \lambda_{y}}=\frac{\lambda_{A_{66}} \lambda_{u_{0}}}{\lambda_{x} \lambda_{y}}=\frac{\lambda_{I_{0}} \lambda_{v_{0}}}{\lambda_{t}{ }^{2}}=\frac{\lambda_{I_{1}} \lambda_{w_{0}}}{\lambda_{t}{ }^{2} \lambda_{y}} \\
\frac{\lambda_{D_{11}} \lambda_{w_{0}}}{\lambda_{x}{ }^{4}}=\frac{\lambda_{D_{22}} \lambda_{w_{0}}}{\lambda_{y}{ }^{4}}=\frac{\lambda_{D_{12}} \lambda_{w_{0}}}{\lambda_{x}{ }^{2} \lambda_{y}{ }^{2}}=\frac{\lambda_{D_{66}} \lambda_{w_{0}}}{\lambda_{x}{ }^{2} \lambda_{y}{ }^{2}}=\frac{\lambda_{D_{16}} \lambda_{w_{0}}}{\lambda_{x}{ }^{3} \lambda_{y}}=\frac{\lambda_{D_{26}} \lambda_{w_{0}}}{\lambda_{x} \lambda_{y}{ }^{3}}=\frac{\lambda_{\bar{N}_{x x}} \lambda_{w_{0}}}{\lambda_{x}{ }^{2}}=\frac{\lambda_{\bar{N}_{y y}} \lambda_{w_{0}}}{\lambda_{y}{ }^{2}} \\
=\frac{\lambda_{\bar{N}_{x y}} \lambda_{w_{0}}}{\lambda_{x} \lambda_{y}}=\lambda_{p}=\frac{\lambda_{I_{0}} \lambda_{w_{0}}}{\lambda_{t}{ }^{2}}=\frac{\lambda_{I_{1}} \lambda_{u_{0}}}{\lambda_{t}{ }^{2} \lambda_{x}}=\frac{\lambda_{I_{1}} \lambda_{v_{0}}}{\lambda_{t}{ }^{2} \lambda_{y}}=\frac{\lambda_{I_{2}} \lambda_{w_{0}}}{\lambda_{x}{ }^{2} \lambda_{t}{ }^{2}}=\frac{\lambda_{I_{2}} \lambda_{w_{0}}}{\lambda_{y}{ }^{2} \lambda_{t}{ }^{2}}
\end{gathered}
$$

Eq. (9) can be obtained by applying the governing equation method to Eq. (5). $\lambda_{I_{i}}$ in Eq. (6)-(8) can subsequently be replaced by Eq. (9).

$$
\lambda_{I_{i}}=\lambda_{h}{ }^{1+i} \lambda_{\rho}(i=0,1 \text { and } 2)
$$

In order to derive appropriate similarity conditions from Eq. (6)-(8), some constraints need to be applied. In this study, Eq. (10) was applied to ensure that the geometrical dimensions of the plate were scaled with the same ratio $\lambda_{D I M}$, avoiding any geometrical distortion.

$$
\lambda_{D I M}=\lambda_{l}=\lambda_{w}=\lambda_{h}=\lambda_{x}=\lambda_{y}=\lambda_{z}
$$

Eq. (11) and (12) are the constraints on the SFs of external loads and displacements respectively; the vectors at different directions need to be scaled consistently [28].

$$
\begin{gathered}
\lambda_{\bar{N}_{e x}}=\lambda_{\bar{N}_{x x}}=\lambda_{\bar{N}_{y y}}=\lambda_{\bar{N}_{x y}} \\
\lambda_{\text {DISP }}=\lambda_{u_{0}}=\lambda_{v_{0}}=\lambda_{w_{0}}
\end{gathered}
$$

By substituting Eq. (9)-(12) into Eq. (6)-(8), the similarity conditions for plates are obtained:

$$
\begin{gathered}
\lambda_{A_{i j}}=\lambda_{A_{11}}=\lambda_{A_{12}}=\lambda_{A_{16}}=\lambda_{A_{22}}=\lambda_{A_{26}}=\lambda_{A_{66}} \\
\lambda_{D_{i j}}=\lambda_{A_{i j}} \lambda_{D I M}{ }^{2}=\lambda_{D_{11}}=\lambda_{D_{12}}=\lambda_{D_{16}}=\lambda_{D_{22}}=\lambda_{D_{26}}=\lambda_{D_{66}} \\
\frac{\lambda_{A_{i j}} \lambda_{D I S P}}{\lambda_{D I M}{ }^{2}}=\frac{\lambda_{D_{i j}} \lambda_{D I S P}}{\lambda_{D I M}{ }^{4}}=\frac{\lambda_{\bar{N}_{e x}} \lambda_{D I S P}}{\lambda_{D I M}{ }^{2}}=\lambda_{p}=\frac{\lambda_{\rho} \lambda_{D I S P} \lambda_{D I M}}{\lambda_{t}{ }^{2}}
\end{gathered}
$$

Based on the concept of dimensional analysis [6], the SFs of modal frequency $(\omega)$ and critical buckling load $\left(\bar{N}_{c r}\right)$ can be intuitively deduced from $\lambda_{t}$ and $\lambda_{\bar{N}_{e x}}$ respectively based on their units if similarity conditions are valid:

$$
\begin{aligned}
\lambda_{\omega} & =\frac{1}{\lambda_{t}} \\
\lambda_{\bar{N}_{c r}} & =\lambda_{\bar{N}_{e x}}
\end{aligned}
$$

Therefore, the scaling laws for plates can be derived from Eq. (15): 


$$
\begin{gathered}
\lambda_{w_{0}}=\lambda_{D I S P}=\frac{\lambda_{p} \lambda_{D I M}{ }^{2}}{\lambda_{A_{i j}}}=\frac{\lambda_{p} \lambda_{D I M}{ }^{4}}{\lambda_{D_{i j}}} \\
\lambda_{\omega}=\sqrt{\frac{\lambda_{A_{i j}}}{\lambda_{\rho} \lambda_{D I M}{ }^{3}}}=\sqrt{\frac{\lambda_{D_{i j}}}{\lambda_{\rho} \lambda_{D I M}{ }^{5}}} \\
\lambda_{\bar{N}_{c r}}=\lambda_{\bar{N}_{e x}}=\lambda_{A_{i j}}=\frac{\lambda_{D_{i j}}}{\lambda_{D I M}{ }^{2}}
\end{gathered}
$$

\subsubsection{I-beam}

The differential governing equation for symmetric laminated rectangular beams can be derived by treating the CLPT as a one-dimensional problem, with the assumption that the investigated laminated beam is long enough to make the effects of Poisson ratio and shear coupling on the deflection negligible [30]. The obtained equation can be also casted in the familiar form used in the classical Euler-Bernoulli beam theory, as described in Eq. (21) [30].

$$
\frac{\partial^{2} w_{0}}{\partial x^{2}}=-D_{11}^{*} M_{x x}=-\frac{M}{E I_{e q}}, \quad M=b M_{x x}
$$

where $D_{i j}^{*}$ denotes the element of the inverse matrix of $[D] . M$ is the total bending moment, which is calculated as the product of $b$, the width of the beam, and $M_{x x}$, the bending moment per unit length. $E I_{e q}$ is the equivalent flexural rigidity of the beam. The governing equation for symmetric laminated long rectangular beams can be subsequently obtained according to Eq. (3):

$$
-\frac{\partial^{2}}{\partial x^{2}}\left(\frac{E I_{e q}}{b} \frac{\partial^{2} w_{0}}{\partial x^{2}}\right)+\bar{N}_{x x} \frac{\partial^{2} w_{0}}{\partial x^{2}}+p=I_{0} \ddot{w}_{0}-I_{2} \frac{\partial^{2} \ddot{w}_{0}}{\partial x^{2}}
$$

Eq. (23) indicates the similarity conditions for rectangular beams, which is derived from Eq. (22) following the similar procedures applied for plates using the governing equation method.

$$
\frac{\lambda_{E I_{e q}} \lambda_{D I S P}}{\lambda_{D I M}{ }^{5}}=\frac{\lambda_{\bar{N}_{x x}} \lambda_{D I S P}}{\lambda_{D I M}{ }^{2}}=\lambda_{p}=\lambda_{D I M} \lambda_{\rho} \lambda_{D I S P} \lambda_{\omega}^{2}
$$

The scaling laws for rectangular beams can be subsequently obtained from Eq. (23):

$$
\begin{gathered}
\lambda_{w_{0}}=\lambda_{D I S P}=\frac{\lambda_{p} \lambda_{D I M}{ }^{5}}{\lambda_{E I_{e q}}} \\
\lambda_{\omega}=\sqrt{\frac{\lambda_{E I_{e q}}}{\lambda_{\rho} \lambda_{D I M}{ }^{6}}} \\
\lambda_{\bar{N}_{c r}}=\lambda_{\bar{N}_{x x}}=\frac{\lambda_{E I_{e q}}}{\lambda_{D I M}{ }^{3}}
\end{gathered}
$$

To apply these scaling laws to the laminated I-shape beam shown in Fig. 2, $E I_{e q}$ can be calculated by superposing the $E I$ values of the top flange, bottom flange and the web (i.e. $E I_{f_{-} t o p}, E I_{f_{-} \text {bottom }}$ and $E I_{w}$ ) using Eq. (27), where $D_{f_{-} \text {top }}^{*} i j$ and $D_{f_{-} \text {bottom } \_i j}^{*}$ denote the elements of the inverse $\left[D_{f_{-} t o p}\right]$ and $\left[D_{f_{-} b o t t o m}\right]$ matrix 
respectively; $\left[D_{f_{-} \text {top }}\right]$ and $\left[D_{f_{-} \text {bottom }}\right]$ represent the adjusted $[D]$ matrix for the top and bottom flanges respectively based on their positions with respect to the centroid of the cross section $\left(Z_{c}\right)$, as defined by Eq. (28) and (29) [33].

$$
\begin{gathered}
E I_{\text {eq }}=E I_{f_{-} \text {top }}+E I_{f_{-} \text {bottom }}+E I_{w} \\
=\frac{b_{f_{-} \text {top }}}{D_{f_{-} \text {top } 11} 11}+\frac{b_{f_{-} \text {bottom }}}{D_{f_{-} \text {bottom_ } 11}^{*}}+\frac{1}{A_{11}^{*} h_{f}}\left[\frac{h_{f} h_{w}{ }^{3}}{12}+h_{w} h_{f}\left(\frac{1}{2} h_{w}+h_{f}-Z_{c}\right)^{2}\right] \\
{\left[D_{f_{-} \text {top }}\right]=[D]+\left(h_{w}+\frac{3}{2} h_{f}-Z_{c}\right)^{2}[A]} \\
{\left[D_{f_{-} \text {bottom }}\right]=[D]+\left(Z_{c}-\frac{1}{2} h_{f}\right)^{2}[A]}
\end{gathered}
$$

\subsubsection{Stiffened plate}

When a structure composed of several components is scaled, although it can be discretised into separate scaling tasks for each component, the consistency in scaling parameters between components needs to be ensured for maintaining structural continuity [13, 28]. Taking the stiffened plate for instance, the SF of each investigated structural response of the plate is required to be coincident with that of the stiffener. This can be realised by equalising Eq. (18)-(20) to Eq. (24)-(26) respectively with a common $\lambda_{D I M}$. By further applying the governing equation method to Eq. (4) and (27), Eq. (30) and (31) are obtained as stricter similarity conditions; $\lambda_{\bar{Q}_{i j}}=1$ since the material applied for scaled models remains the same as the prototype in the current study.

$$
\begin{gathered}
\lambda_{A_{i j}}=\lambda_{\bar{Q}_{i j}} \lambda_{\text {COORD }}=\lambda_{D I M}, \quad \lambda_{D_{i j}}=\lambda_{\bar{Q}_{i j}} \lambda_{\text {COORD }}{ }^{3}=\lambda_{D I M}{ }^{3} \\
\lambda_{E I_{e q}}=\lambda_{D I M}{ }^{4}
\end{gathered}
$$

Then by replacing $\lambda_{A_{i j}}, \lambda_{D_{i j}}$ and $\lambda_{E I_{e q}}$ in Eq. (18)-(20) and (24)-(26) with Eq. (30) and (31), Eq. (32)-(34) are finally obtained as more generic (also stricter) scaling laws which apply not only to the plate and the I-beam, but also to the stiffened plate and more complex structures.

$$
\begin{gathered}
\lambda_{w_{0}}=\lambda_{D I S P}=\lambda_{p} \lambda_{D I M} \\
\lambda_{\omega}=\sqrt{\frac{1}{\lambda_{\rho} \lambda_{D I M}^{2}}} \\
\lambda_{\bar{N}_{c r}}=\lambda_{\bar{N}_{e x}}=\lambda_{D I M}
\end{gathered}
$$

\subsection{Partial similitude design using the GAPSD method}

As discussed in Section 1.2, when the ply thickness cannot be scaled due to manufacturing constraints, the conventional partial similitude design (i.e. CPSD) method illustrated in Fig. 1(c) invalidates the similarity conditions, which is likely to degrade the accuracy of prototype predictions using scaled models based on the scaling laws [20-25]. In the present study, a GA-based partial similitude design method (i.e. GAPSD) has been 
applied to improve the prediction accuracy compared with the CPSD method. Fig. 4 illustrates the flowchart of the GAPSD method, applying to both plates and beams. Basically, the stiffness of the prototype is firstly evaluated based on its stacking sequence. The target stiffness of the scaled model can be then calculated following the similarity conditions (in terms of stiffness properties). GA is subsequently applied to obtain an optimised stacking sequence for the scaled model, which best meets the similarity conditions despite the scaling distortion in ply thickness. The optional ply orientations for each ply are confined to $0^{\circ}, 90^{\circ}$ and $\pm 45^{\circ}$, being consistent with the prototype. This new method aims to allow the scaling laws to be used in partial similitude design with improved accuracy.

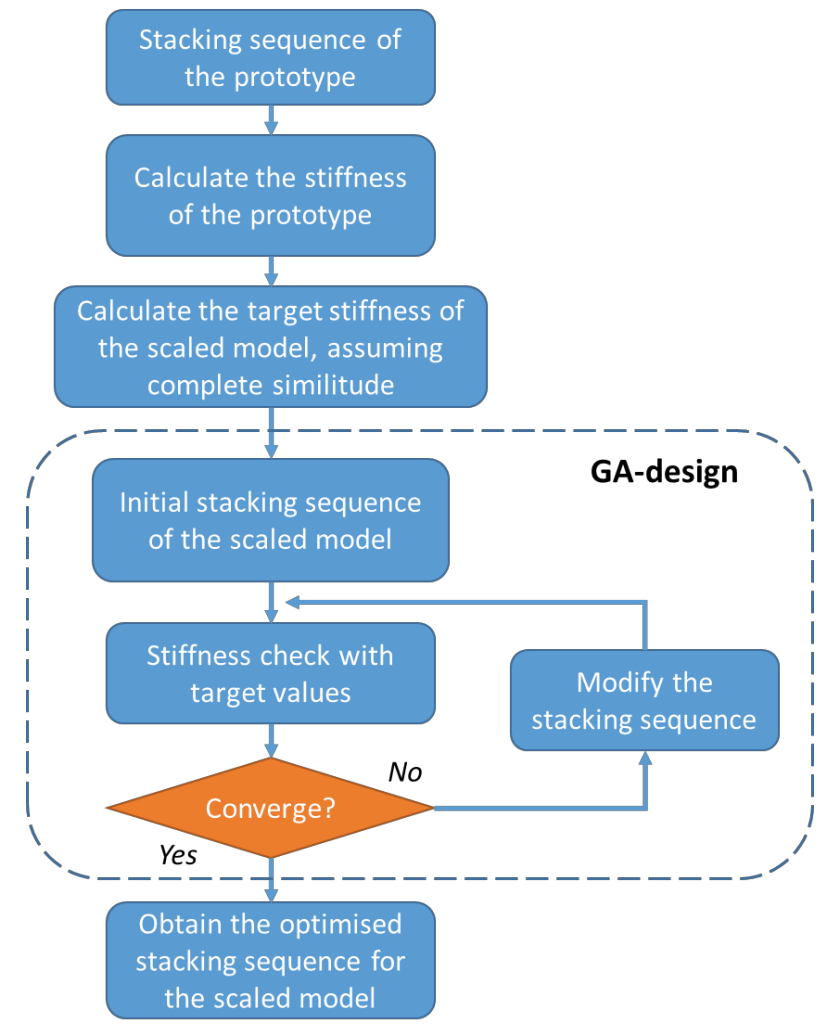

Fig. 4. Flowchart of the GAPSD method.

For the scaling of plates, Eq. (13), (14) and (30) are the required similarity conditions in terms of laminate stiffness matrices. Given a specified $\lambda_{D I M}$, Eq. (35) was used as the objective function of GA to find the stacking sequence best satisfying the similarity conditions when the ply thickness is not scaled; $F U N C_{\text {plate }}=0$ indicates complete similarity with Eq. (13), (14) and (30) being satisfied. $A_{i j}^{\text {tgt }}$ and $D_{i j}^{\text {tgt }}$ represent the elements of the target $[A]$ and $[D]$ matrix of the scaled model to be designed, and can be described by Eq. (36), which is derived from Eq. (30). Being consistent with the prototype, the constraint of symmetry in stacking sequence was applied during the design process hence the $[B]$ matrix was neglected. $A_{16}^{m}=0$ and $A_{26}^{m}=0$ were also used as constraints in the present study for balanced laminates. During the GA design process, the accuracy of the scaled $[D]$ matrix was prioritised over the scaled $[A]$ matrix, considering the dominant role of $[D]$ in governing the out-of-plane behaviour of the plate. It is also expected that defining partiality to certain matrix elements in Eq. 
(35) can further improve the prediction accuracy of specific prototype responses. However, it requires considerable sensitivity analysis to work out appropriate weighting factors for each matrix element, which is beyond the scope of this paper.

$$
\begin{gathered}
F U N C_{\text {plate }}=\frac{1}{4}\left[\left(\frac{A_{11}^{m}-A_{i j}^{\text {tgt }}}{A_{i j}^{t g t}}\right)^{2}+\left(\frac{A_{12}^{m}-A_{12}^{t g t}}{A_{12}^{t g t}}\right)^{2}+\left(\frac{A_{22}^{m}-A_{22}^{t g t}}{A_{22}^{t g t}}\right)^{2}+\left(\frac{A_{66}^{m}-A_{66}^{t g t}}{A_{66}^{t g t}}\right)^{2}\right] \\
+\frac{1}{6}\left[\left(\frac{D_{11}^{m}-D_{i j}^{t g t}}{D_{i j}^{t g t}}\right)^{2}+\left(\frac{D_{12}^{m}-D_{12}^{t g t}}{D_{12}^{t g t}}\right)^{2}+\left(\frac{D_{22}^{m}-D_{22}^{t g t}}{D_{22}^{t g t}}\right)^{2}+\left(\frac{D_{66}^{m}-D_{66}^{t g t}}{D_{66}^{t g t}}\right)^{2}\right. \\
\left.+\left(\frac{D_{16}^{m}-D_{16}^{t g t}}{D_{16}^{t g t}}\right)^{2}+\left(\frac{D_{26}^{m}-D_{26}^{t g t}}{D_{26}^{t g t}}\right)^{2}\right] \\
A_{i j}^{t g t}=\frac{A_{i j}^{p}}{\lambda_{A_{i j}}}=\frac{A_{i j}^{p}}{\lambda_{d i m}}, \quad D_{i j}^{t g t}=\frac{D_{i j}^{p}}{\lambda_{D_{i j}}}=\frac{D_{i j}^{p}}{\lambda_{d i m}{ }^{3}}
\end{gathered}
$$

For scaled I-beams, Eq. (31) is the required similarity condition in terms of flexural rigidity, which is linked to laminate properties as shown in Eq. (27)-(29). Based on Eq. (31), the target $E I_{e q}$ for scaled I-beams, $E I_{e q}^{\text {tgt }}$, can be expressed as Eq. (37). Therefore, Eq. (38) was used as the objective function of GA for designing the stacking sequence of scaled I-beams.

$$
\begin{gathered}
E I_{e q}^{t g t}=\frac{E I_{e q}^{p}}{\lambda_{E I_{e q}}}=\frac{E I_{e q}^{p}}{\lambda_{D I M}{ }^{4}} \\
F U N C_{\text {beam }}=\left|\frac{E I_{e q}^{m}-E I_{e q}^{t g t}}{E I_{e q}^{t g t}}\right|
\end{gathered}
$$

The values of key GA parameters that have been applied in the present study are listed in Table 2; the exact values of the population size, the crossover fraction and the elite count depend on the ply number of the scaled model hence the associated value ranges are provided.

Table 2. The values of key GA parameters applied in this study [34, 35].

\begin{tabular}{|l|l|l|l|l|l|}
\hline Population size & $\begin{array}{l}\text { Function } \\
\text { tolerance }\end{array}$ & $\begin{array}{l}\text { Max stall } \\
\text { generations }\end{array}$ & $\begin{array}{l}\text { Max } \\
\text { generations }\end{array}$ & $\begin{array}{l}\text { Crossover } \\
\text { fraction }\end{array}$ & Elite count \\
\hline 200 to 500 & $1 \mathrm{E}-8$ & 200 & 500 & 0.8 to 0.9 & $\begin{array}{l}0.05 \text { to } 0.1 \times \\
\text { Population size }\end{array}$ \\
\hline
\end{tabular}

\section{Comparison between the prototype and the predictions using scaled models}

Predictions of the prototype structural behaviour using scaled models were firstly applied to the plate and the Ibeam separately using the derived scaling laws before being applied to the stiffened plate. Both the CPSD and GAPSD methods have been applied to design the scaled models, considering partial similarity resulting from 
the distortion in ply thickness (i.e. ply thickness equals $0.25 \mathrm{~mm}$ for each scaled model, being identical with the prototype).

\subsection{Plate}

The resultant stacking sequences at different scaling levels for the plate are summarised in Table 3; the stacking sequence of the prototype plate $\left(\lambda_{D I M}=1\right)$ is also included as a comparison. It is noted that the CPSD method can only be applied with limited SFs since the stacking pattern in the prototype needs to be retained for the scaled model, as illustrated in Fig. 1(c).

Table 3. Stacking sequences of scaled plate models

\begin{tabular}{|c|c|c|c|c|}
\hline \multicolumn{2}{|l|}{$\mathrm{SF}\left(\lambda_{D I M}\right)$} & No. of plies & CPSD method & GAPSD method \\
\hline Prototype & 1 & 128 & \multicolumn{2}{|c|}{$\left[(95 / 45 / 0 /-45)_{16}\right]_{\mathrm{s}}$} \\
\hline \multirow{4}{*}{$\begin{array}{l}\text { SFs applicable } \\
\text { to both methods }\end{array}$} & 2 & 64 & {$\left[(95 / 45 / 0 /-45)_{8}\right]_{\mathrm{s}}$} & $\begin{array}{l}{\left[45 / 0 / \mp 45 / 90_{2} / 0 /-45_{2} / 90_{3} / 45 / 0_{3} /-\right.} \\
\left.45_{2} / 45_{3} / 0 /-45 / 90 /-45 / 0 / 45 / 90 / 45 / 0 /-45 / 0\right]_{\mathrm{s}}\end{array}$ \\
\hline & 4 & 32 & {$\left[(95 / 45 / 0 /-45)_{4}\right]_{\mathrm{s}}$} & $\begin{array}{l}{[45 / 90 /-45 / 0 / 90 /-} \\
\left.45 / 0_{2} / \pm 45 / 45 / 90 / 0 / \pm 45 / 0\right]_{\mathrm{s}}\end{array}$ \\
\hline & 8 & 16 & {$\left[(95 / 45 / 0 /-45)_{2}\right]_{\mathrm{s}}$} & {$[45 / 0 / 90 /-45 / 90 /-45 / 90 / 45 / \mathrm{s}$} \\
\hline & 16 & 8 & {$[95 / 45 / 0 /-45]_{\mathrm{s}}$} & {$[45 / 90 / 0 /-45]_{\mathrm{s}}$} \\
\hline \multirow{8}{*}{$\begin{array}{l}\text { Additional SFs } \\
\text { (only applicable } \\
\text { to the GAPSD } \\
\text { method) }\end{array}$} & $32 / 13$ & 52 & \multirow{8}{*}{ N/A } & $\begin{array}{l}{\left[45 / 90 /-45 / 0 / \bar{\mp} 45 / 0_{2} / 90_{2} / 45 / 90 / 45 / 90 /-\right.} \\
\left.45_{2} / 0_{2} /-45_{2} / 0 / 90 / \bar{\mp} 45 / 45_{2}\right]_{\mathrm{s}}\end{array}$ \\
\hline & $64 / 13$ & 26 & & {$\left[90 / 45 /-45 / 0_{2} / \bar{\mp} 45 / 90 / 45 / 0 / 90_{2} /-45\right]_{\mathrm{s}}$} \\
\hline & 6.4 & 20 & & {$\left[90 / 0 / \pm 45 / \pm 45 /-45 / 0_{2} / 45\right]_{\mathrm{s}}$} \\
\hline & $64 / 7$ & 14 & & {$[45 / 90 / 0 /-45 / 0 / \bar{\mp} 45]_{\mathrm{s}}$} \\
\hline & $32 / 3$ & 12 & & {$[45 / 90 / 0 /-45 / 0 / 90]_{\mathrm{s}}$} \\
\hline & 12.8 & 10 & & {$\left[45 / 90 / 0_{2} /-45\right]_{\mathrm{s}}$} \\
\hline & $64 / 3$ & 6 & & {$[45 / 90 /-45]_{\mathrm{s}}$} \\
\hline & 32 & 4 & & {$[ \pm 45]_{\mathrm{s}}$} \\
\hline
\end{tabular}


The structural behaviour of the prototype plate was predicted using scaled plate models following the generic scaling laws described by Eq. (32)-(34). $\lambda_{p}=1$ was defined for the applied pressure, and the applied edge loads $\left(\bar{N}_{e x}\right)$ were appropriately scaled following Eq. (20). The absolute errors of the prediction with varying SFs are calculated using Eq. (39), where $R_{P R O T O}$ and $R_{P R E D}$ stand for the structural response obtained directly from the prototype model, and the corresponding prediction using the scaled model, respectively. The obtained results are displayed in Fig. 5, with schematic diagrams illustrating the corresponding structural responses. It can be seen that the CPSD method leads to less accurate prediction with greater SFs, which is consistent with the conclusion in [20-25]. This is attributed to the aggravated mismatch in Eq. (13), (14) and (30) when a greater SF is applied. By contrast, the GAPSD method is demonstrated to be capable of improving the prediction accuracy of the CPSD method, regardless of the selected SF, BCs, and structural response.

$$
\text { Prediction error }=\left|\frac{R_{P R E D}-R_{\text {PROTO }}}{R_{\text {PROTO }}}\right| \times 100 \%
$$
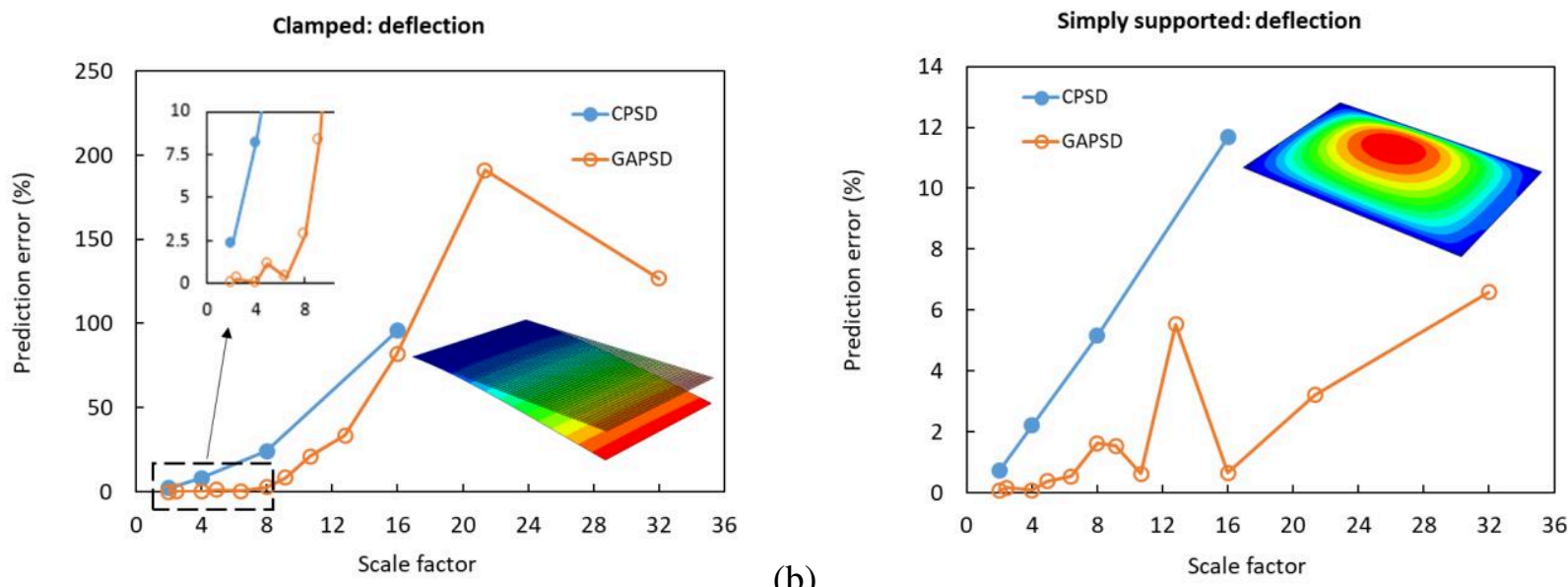

(a)

(b)
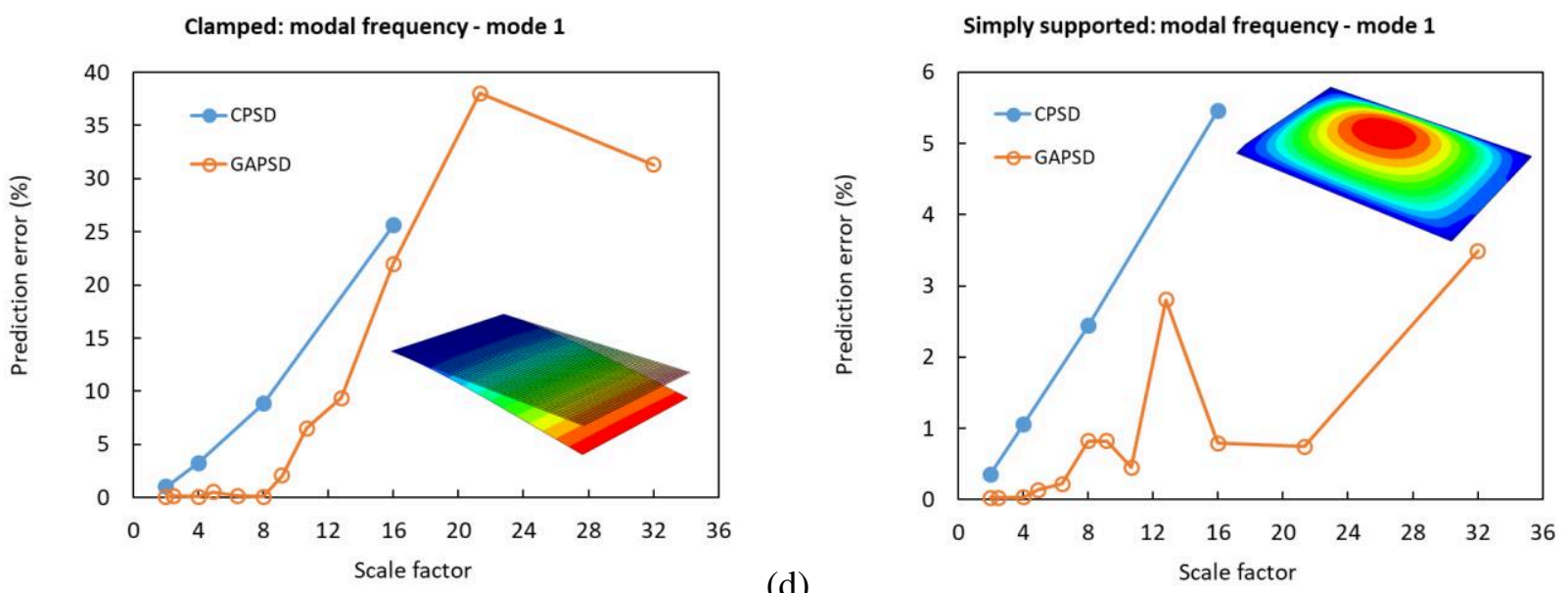

(c) 

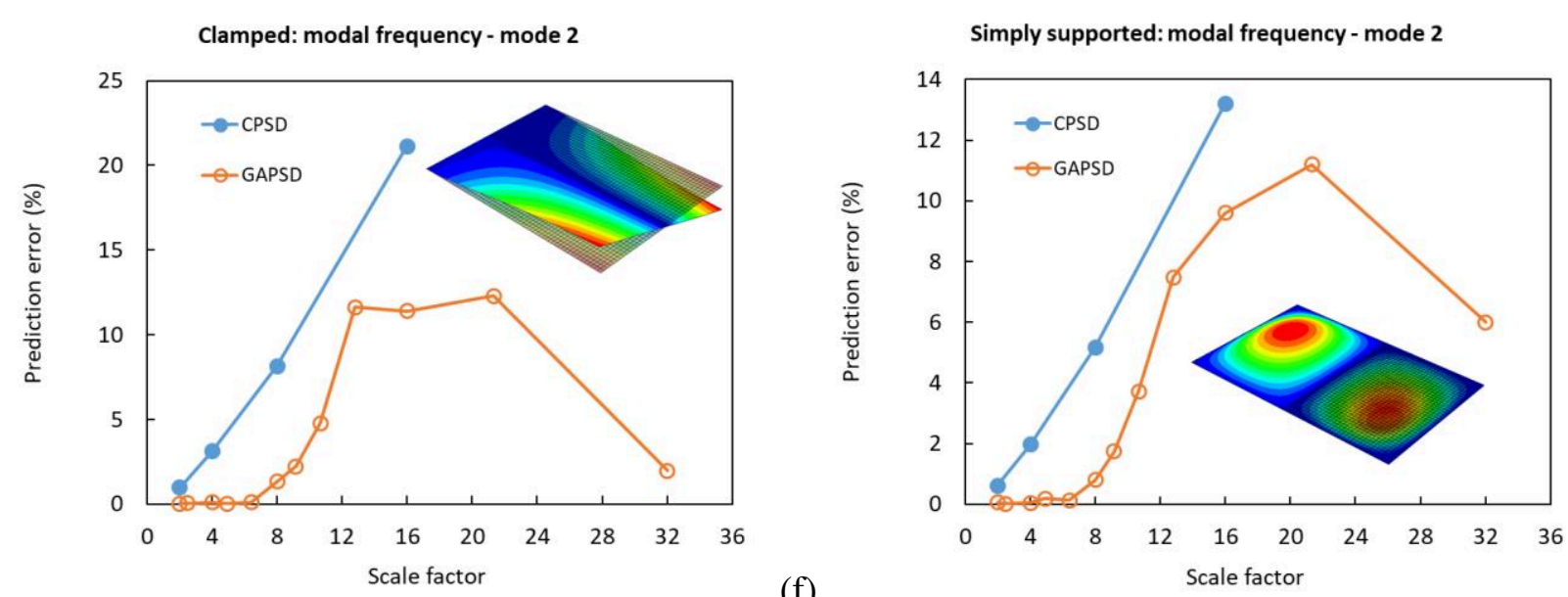

(e)

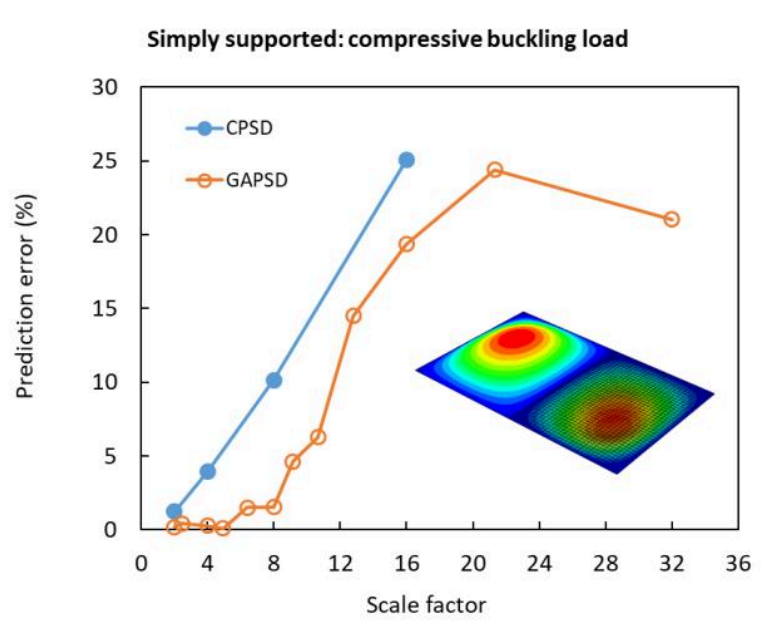

(g)

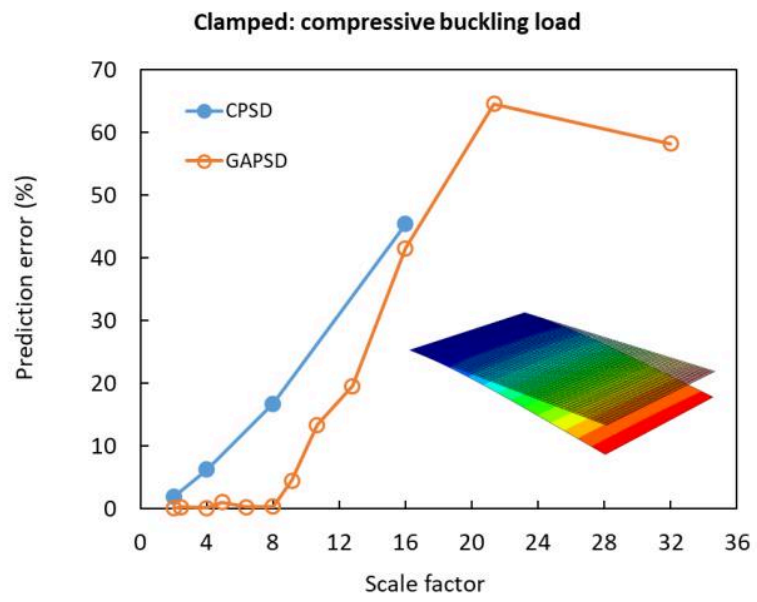

(h)

Fig. 5. Absolute errors (\%) of prototype prediction using scaled plate models in (a)(b) deflection, (c)(d) first modal frequency, (e)(f) second modal frequency, (g)(h) compressive buckling load with different BCs: (a)(c)(e)(g) clamped, (b)(d)(f)(h) simply supported.

The average prediction improvement achieved by applying the GAPSD method for each structural response is calculated based on the prediction results at $\lambda_{D I M}=2,4,8$ and 16 using Eq. (40), where CPSD error and $G A P S D_{\text {error }}$ denote the prediction error (as displayed in Fig. 5) resulting from the CPSD and GAPSD methods respectively. The calculated results are presented in Fig. 6, implying an improvement being up to $87 \%$ by applying the GAPSD instead of the CPSD method. 


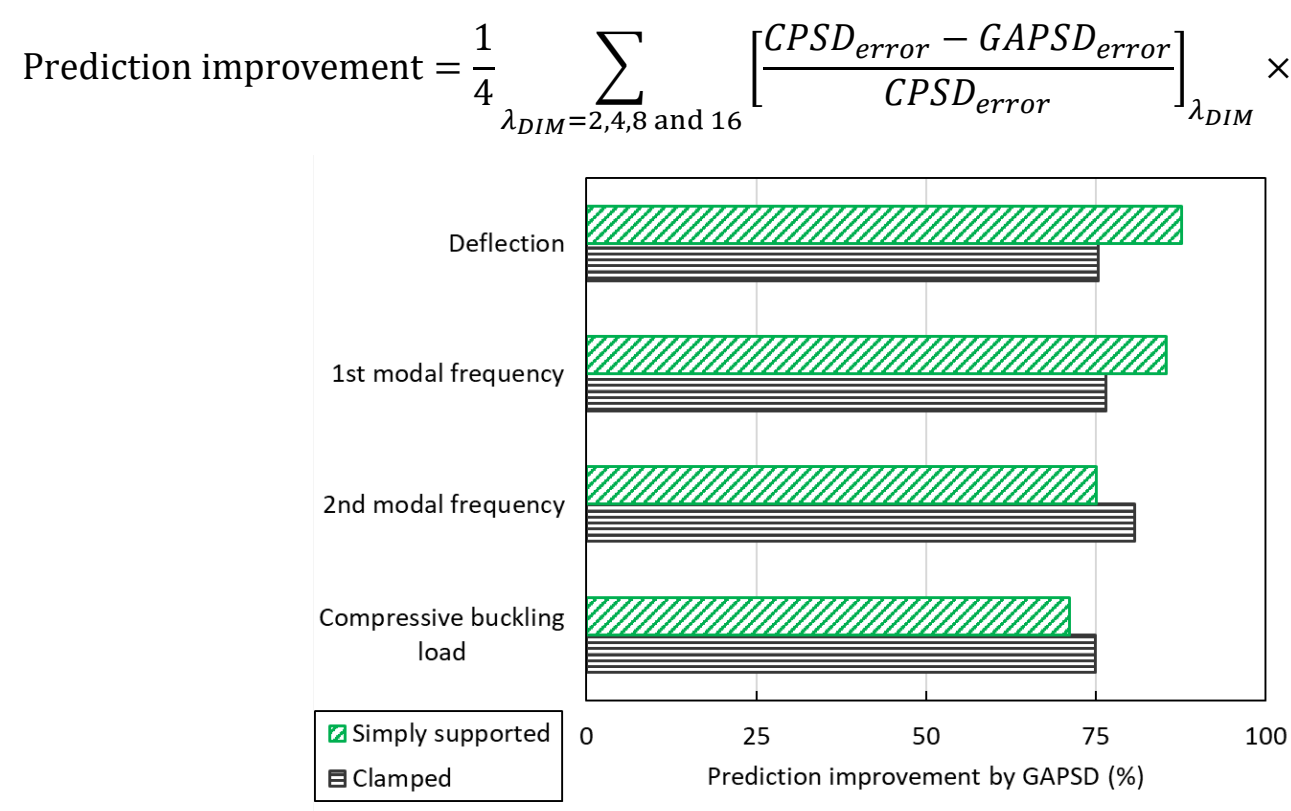

Fig. 6. Average improvement (for $\lambda_{D I M}=2,4,8$ and 16) of the prototype prediction by applying the GAPSD method instead of the CPSD method.

Another advantage of the GAPSD method is that it enriches the options of applicable SFs, not being restricted by the prototype stacking pattern anymore. It is noteworthy from Fig. 5 that although the GAPSD method is still superior to the CPSD method at high scaling levels, its prediction accuracy becomes unstable. This phenomenon is attributed to the limited number of plies when a relatively high SF is applied, which restricts the possibility of achieving satisfactory predictions for all the investigated responses simultaneously.

When investigating the modal behaviour of a structure, modal shapes are also important in addition to modal frequencies. Fig. 7 takes the second mode (torsional) of the clamped plate as an example to compare the modal shape of the prototype and the scaled models, implying a variance in modal shapes with different $\lambda_{\text {dim }}$. This variance is also caused by partial similarity, which hampers reconstructing a scaled stiffness distribution being perfectly consistent with similarity conditions. In the application of the GAPSD method, it will always need to check that the important modes of the prototype are not missed and are properly represented by the scaled model.

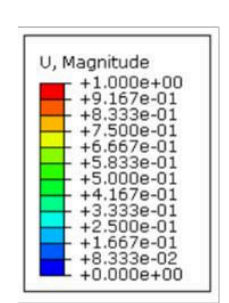

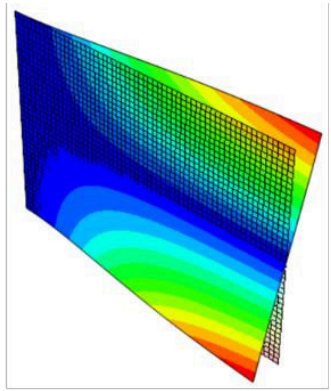

(a) Prototype

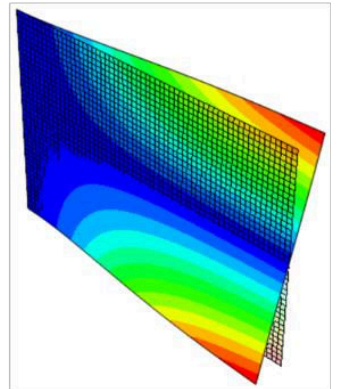

(b) $\lambda_{\text {dim }}=4$

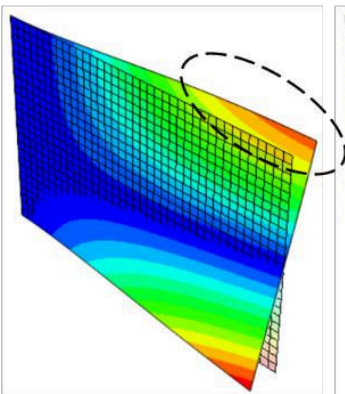

(c) $\lambda_{\text {dim }}=12.8$

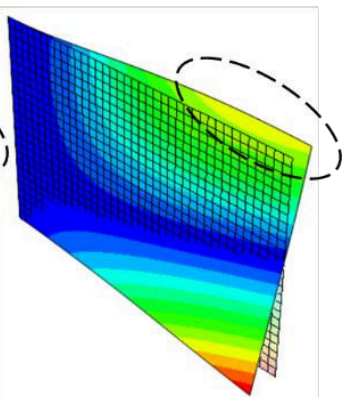

(d) $\lambda_{\text {dim }}=32$

Fig. 7. Difference in the $2^{\text {nd }}$ modal shape of the clamped plate between the prototype and the scaled models.

\subsection{I-beam}


Both the CPSD and GAPSD methods have also been applied to the scaled I-beam models. The obtained stacking sequences at different scaling levels are summarised in Table 4.

Table 4. Stacking sequences of scaled I-beam models

\begin{tabular}{|c|c|c|c|c|}
\hline \multicolumn{2}{|l|}{$\operatorname{SF}\left(\lambda_{D I M}\right)$} & No. of plies & CPSD method & GAPSD method \\
\hline Prototype & 1 & 48 & \multicolumn{2}{|c|}{$\left[(0 / \pm 45 / 90)_{6}\right]_{\mathrm{s}}$} \\
\hline \multirow{3}{*}{$\begin{array}{l}\text { SFs applicable } \\
\text { to both methods }\end{array}$} & 2 & 24 & {$\left[(0 / \pm 45 / 90)_{3}\right]_{\mathrm{s}}$} & {$\left[ \pm 45 / 90 / 0_{3} / \bar{\mp} 45 / 90_{2} / \bar{\mp} 45\right]_{\mathrm{s}}$} \\
\hline & 3 & 16 & {$\left[(0 / \pm 45 / 90)_{2}\right]_{\mathrm{s}}$} & {$\left[45 / 0 /-45_{2} / 90_{2} / 0 / 45\right]_{\mathrm{s}}$} \\
\hline & 6 & 8 & {$[0 / \pm 45 / 90]_{\mathrm{s}}$} & {$[-45 / 0 / 90 / 45]_{\mathrm{s}}$} \\
\hline \multirow{3}{*}{$\begin{array}{l}\text { Additional SFs } \\
\text { (only applicable } \\
\text { to the GAPSD } \\
\text { method) }\end{array}$} & 4 & 12 & \multirow{3}{*}{ N/A } & {$\left[45 / 0 / 90_{2} / 0 / 90\right]_{\mathrm{s}}$} \\
\hline & 8 & 6 & & {$[45 / 0 / 90]_{\mathrm{s}}$} \\
\hline & 12 & 4 & & {$[90 / 0]_{\mathrm{s}}$} \\
\hline
\end{tabular}

Similarly with the plate, the structural behaviour of the prototype I-beam was predicted using scaled I-beam models following the generic scaling laws described by Eq. (32)-(34). $\lambda_{p}=1$ was defined for the applied pressure, and the axial load $\left(\bar{N}_{x x}\right)$ was appropriately scaled following Eq. (26).

The absolute errors of the prediction with varying SFs, which are calculated using Eq. (39), are summarised in Fig. 8, demonstrating similar features as plate scaling. However, it can be seen that the GAPSD method does not always improve the prediction of the CPSD method. This may be attributed to the one-dimensional assumption of the applied beam theory, which assumes that the bending behaviour only depends on $D_{11}^{*}$ and $A_{11}^{*}$ while neglecting the effects of the Poisson ratio and shear coupling on the deflection. Despite this, the GAPSD method can still be regarded as an effective tool for designing scaled I-beams since all the prototype prediction errors are within $\pm 5 \%$, except at the highest scaling level $\left(\lambda_{D I M}=12\right)$ when there only 2 plies applicable for design (4 plies considering symmetry).
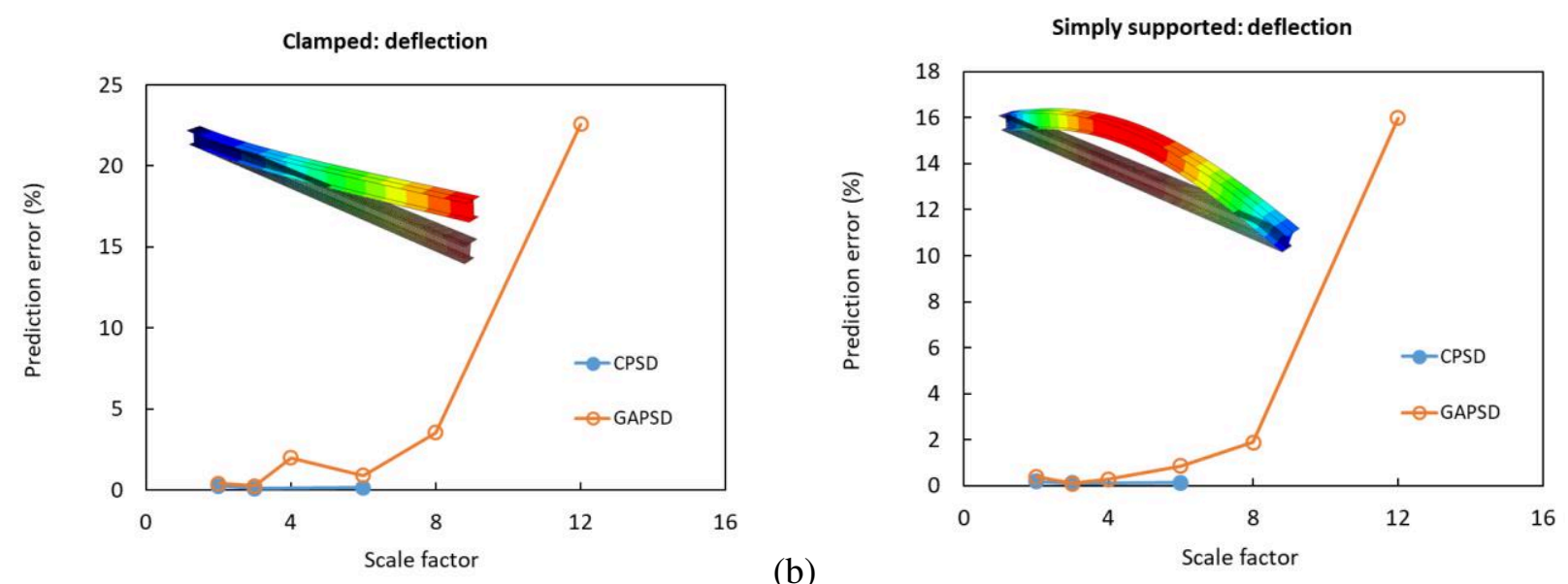

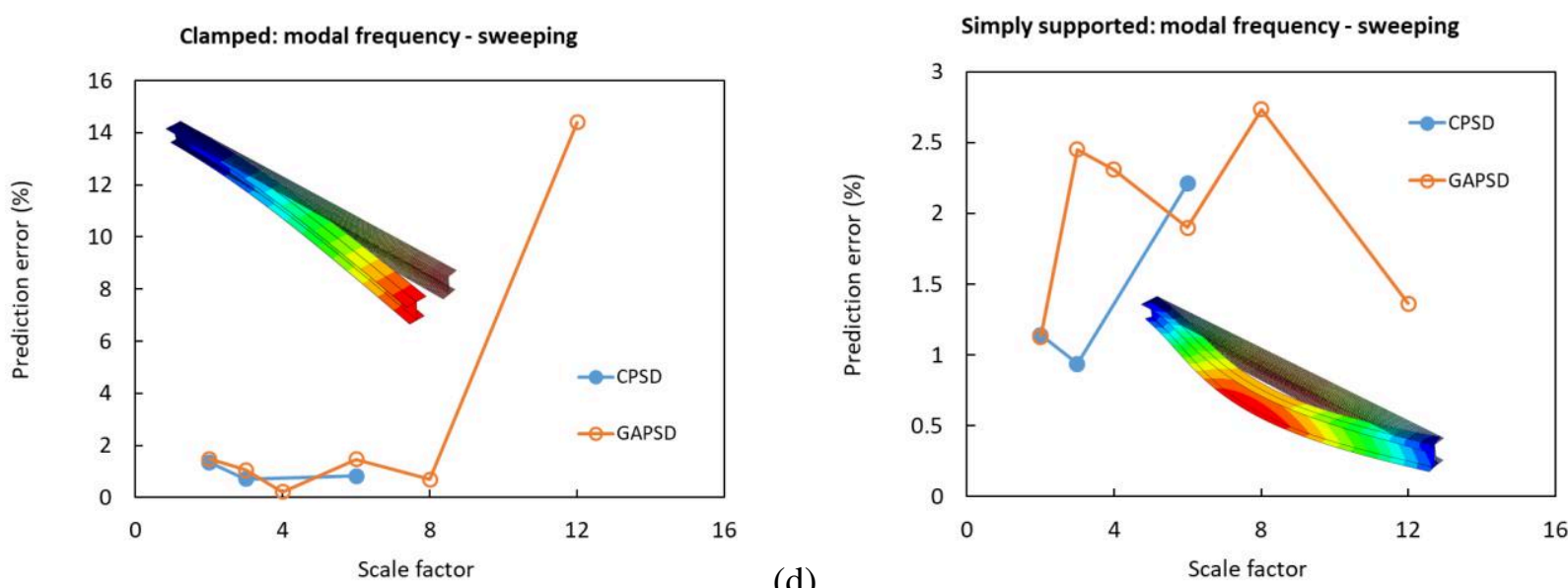

(c)

(d)
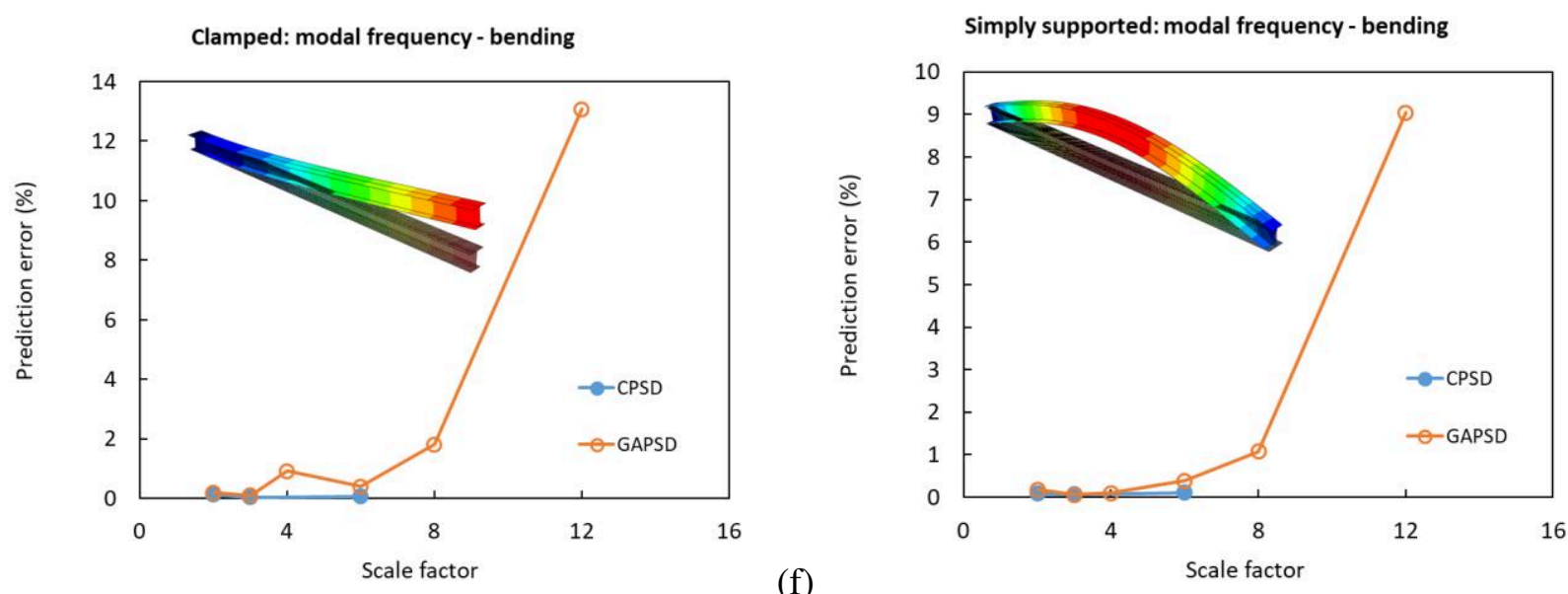

(e)
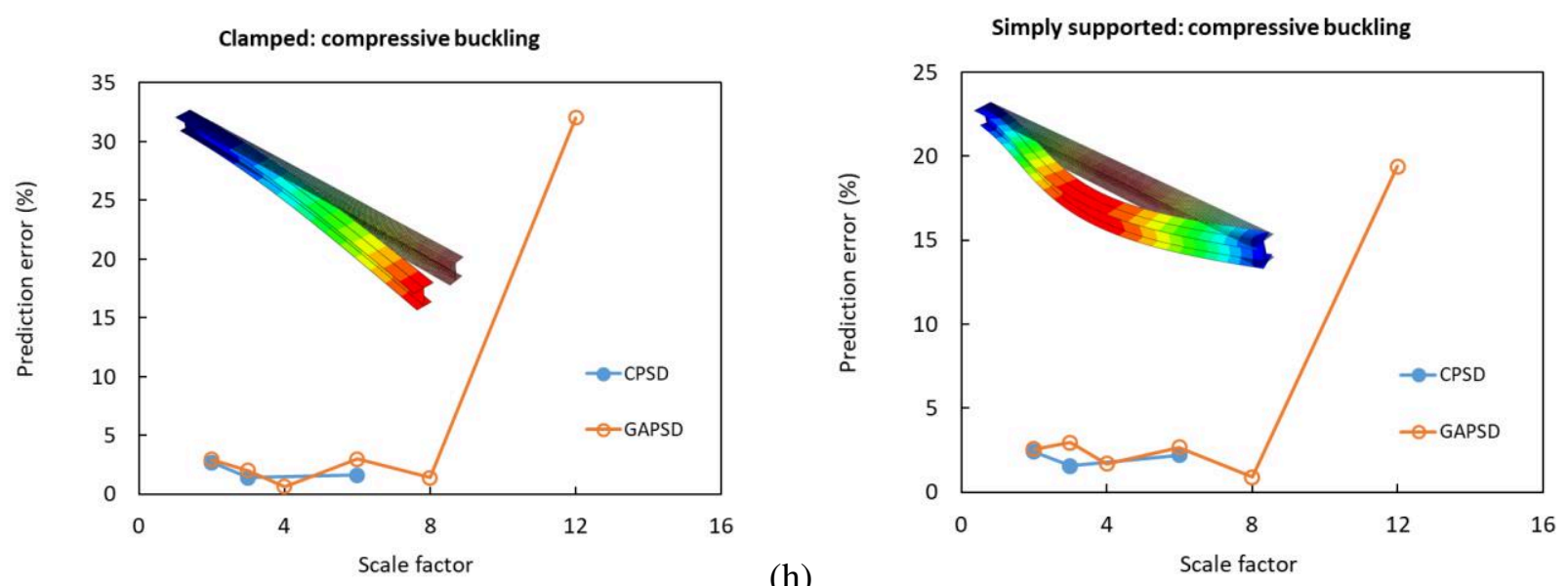

Fig. 8. Absolute errors (\%) of prototype prediction using scaled I-beam models in (a)(b) deflection, (c)(d) first modal frequency, (e)(f) second modal frequency, $(\mathrm{g})(\mathrm{h})$ compressive buckling load with different BCs: (a)(c)(e)(g) clamped, (b)(d)(f)(h) simply supported.

\subsection{Stiffened plate}

The scaled stiffened plate models were developed based on the stacking sequences obtained from the GAPSD method, which were summarised in Table 3 and Table 4 for the scaled plate and I-beam models respectively. The pressure and edge loads applied to the scaled stiffened plate models are consistent with those applied to the scaled plate models, which have been introduced in Section 3.1. To ensure the plate and stiffeners being scaled 
consistently, three common $\lambda_{D I M}$ values (i.e. $\lambda_{D I M}=2,4$ and 8 ) were chosen according to Table 3 and Table 4 . The errors of the prototype prediction using the scaled stiffened plate models are listed in Table 5, following the generic scaling laws described by Eq. (32)-(34). Comparing Table 5 with the results depicted in Fig. 5 and Fig. 8, the prediction errors for stiffened plate remain at similar levels as those for the individual plate and Ibeam at corresponding $\lambda_{D I M}$. This demonstrates the feasibility of the scaling methodology explained in Section 2.2.3.

Table 5. Errors (\%) of the prototype prediction using scaled stiffened plate models with stacking sequences of the plate and stiffeners obtained from the GAPSD method.

\begin{tabular}{|l|l|l|l|l|l|}
\hline \multicolumn{2}{|l|}{ SF $\left(\boldsymbol{\lambda}_{\text {DIM }}\right)$} & Deflection & $\begin{array}{l}\text { Modal frequency } \\
- \text { mode 1 }\end{array}$ & $\begin{array}{l}\text { Modal frequency } \\
- \text { mode 2 }\end{array}$ & $\begin{array}{l}\text { Compressive } \\
\text { buckling load }\end{array}$ \\
\hline \multirow{3}{*}{ Clamped } & 2 & -0.90 & 0.35 & 0.09 & 0.71 \\
\cline { 2 - 6 } & 4 & -4.62 & 2.14 & -0.06 & 4.33 \\
\cline { 2 - 6 } & 8 & 1.25 & 0.41 & -0.88 & -0.02 \\
\hline \multirow{3}{*}{$\begin{array}{l}\text { Simply } \\
\text { supported }\end{array}$} & 2 & -0.24 & 0.12 & -0.07 & 0.24 \\
\cline { 2 - 6 } & 4 & 0.22 & -0.22 & -0.96 & -0.14 \\
\cline { 2 - 6 } & 8 & 2.35 & -1.21 & -2.37 & -2.88 \\
\hline
\end{tabular}

\section{Scaling of the wing box}

\subsection{Prototype wing box model}

In the present study, a wing box model was chosen as the prototype to demonstrate the applicability of the proposed GAPSD method to complex composite structures. The wing box model, as shown in Fig. 9, was developed using Siemens NX 9.0 based on sizes required for an A320 size wing box structure. This is a typical wing box structure which is composed of top and bottom skin, front spar, rear spar and ribs, as displayed in Fig. 9(b). The panel of each component can be regarded as plates or shells considering their low thickness compared with their in-plane dimensions. Secondary structures of the wing, such as the leading edge, trailing edge, and landing gear bay are not considered in this study. IM7/8552 has been chosen as the material applied to all the components of this wing box model, with its key properties being listed in Table 1. It is noted that the material selection here does not represent the reality in A320, but is simply used as an assumption in the current study. The applied prototype stacking sequences for each component are listed in Table 6, referring to [36]. The ply thickness is $0.125 \mathrm{~mm}$, being identically applied to each component. 

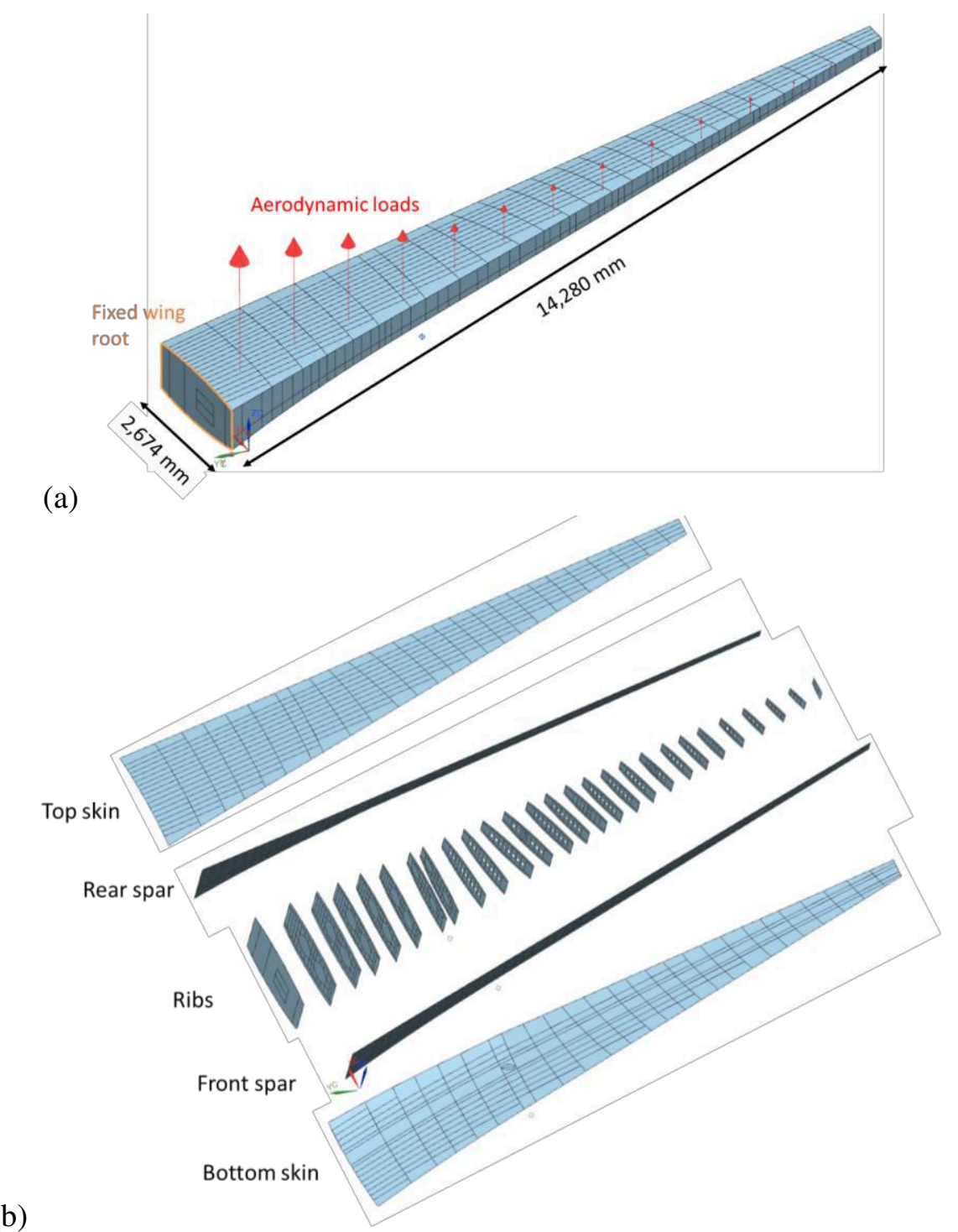

Fig. 9. A320 size wing box model: (a) dimensions, applied loads and BCs and (b) structural discretisation.

The structural behaviour of this wing box structure was analysed using MSC Nastran, including the deflection under static bending, the modal behaviour and the linear buckling behaviour. Meshing was implemented using four-node quadrilateral shell elements (i.e. CQUAD4) for each component. For this wing box structure, the modelling efficiency would be significantly reduced if stiffeners were modelled using shell elements to consider the effects of stacking sequence. Therefore, stiffeners (including stringers attached to the skin) were not modelled in this work as a trade-off between structural complexities and modelling efficiency. This simplification hardly affects the feasibility of this study since the purpose is to validate the robustness of the proposed GAPSD method, rather than carrying out explicit structural analysis of a wing. As illustrated in Fig. 9(a), the wing root has been fixed as the applied BCs. 1g equivalent aerodynamic loads have also been defined using the SMT (shear, moment, torsion) method [37].

Table 6. Stacking sequence for each component of the prototype and the scaled wing box models.

\begin{tabular}{|l|l|l|l|l|}
\hline Model & Skin (top \& bottom) & Front spar & Rear spar & Ribs \\
\hline
\end{tabular}




\begin{tabular}{|l|l|l|l|l|}
\hline Prototype & {$\left[00_{2} /\left(45 / 90 /-45 / 0_{2}\right)_{6}\right]_{\mathrm{s}}$} & {$[ \pm 45 / 0 / \pm 45 / 90]_{3 \mathrm{~s}}$} & {$[ \pm 45 / 0 / \pm 45 / 90 / \pm 45]_{3 \mathrm{~s}}$} & {$\left[(0 / 90 / \pm 45 / 90 / 0)_{4}\right]_{\mathrm{s}}$} \\
\hline $\begin{array}{l}1 / 2 \text { scaled } \\
\text { model }\end{array}$ & $\begin{array}{l}{\left[90 / 0 /-45 / 0 / 45 / 0_{2} /-\right.} \\
\left.45 / \pm 45 / 0_{2} / 45 / 0 / 90_{2}\right]_{\mathrm{s}}\end{array}$ & $\begin{array}{l}{[\mp 45 / 0 / 90 / \pm 45 / 45} \\
/ 90 /-45 / 0 / \mp 45]_{\mathrm{s}}\end{array}$ & $\begin{array}{l}{[-45 / \mp 45 / 0 /-} \\
45_{2} / 902 / \pm 45 / 45 / 0 / \pm 45 / \\
\left.45_{2}\right]_{\mathrm{s}}\end{array}$ & $\begin{array}{l}{[90 / 0 / \pm 45 / 0 / 90 / 0 /-} \\
45 / 90 / 45 / 90 / 0]_{\mathrm{s}}\end{array}$ \\
\hline $\begin{array}{l}1 / 4 \text { scaled } \\
\text { model }\end{array}$ & {$[0 / 90 / \pm 45 / 0 / \mp 45 / 0]_{\mathrm{s}}$} & {$[ \pm 45 / 0 / 90 / \mp 45]_{\mathrm{s}}$} & {$[ \pm 45 / 0 / 90 / \mp 45 / \mp 45]_{\mathrm{s}}$} & {$[90 / 0 / \pm 45 / 0 / 90]_{\mathrm{s}}$} \\
\hline $\begin{array}{l}1 / 8 \text { scaled } \\
\text { model }\end{array}$ & {$[0 / 45 / 90 /-45]_{\mathrm{s}}$} & {$[ \pm 45 / 0]_{\mathrm{s}}$} & {$[ \pm 45 / 0 / 90]_{\mathrm{s}}$} & {$\left[0 / 90_{2}\right]_{\mathrm{s}}$} \\
\hline $\begin{array}{l}1 / 8 \text { scaled } \\
\text { EDS model }\end{array}$ & {$[15 / 75 /-45 / 0]_{\mathrm{s}}$} & {$[30 / 90 /-30]_{\mathrm{s}}$} & {$[ \pm 45 / 0 / 90]_{\mathrm{s}}$} & {$[15 / 90 /-15]_{\mathrm{s}}$} \\
\hline
\end{tabular}

\subsection{Comparison between the prototype wing box behaviour and the predictions using scaled models}

Scaled wing box models were developed by assembling the components being scaled using the same SF; the dimensions of each component were perfectly scaled without any geometric distortion. For each component, the GAPSD method was applied to find the 'best-match' stacking sequence at each scaling level, following the process elaborated in Section 2. The ply orientation options applied for designing scaled models are $0^{\circ}, \pm 45^{\circ}$ and $90^{\circ}$, being consistent with the prototype. The effects of enlarging the design space (EDS) of the stacking sequence were also investigated by adding $\pm 15^{\circ}, \pm 30^{\circ}, \pm 60^{\circ}$ and $\pm 75^{\circ}$ as additional ply orientation options for the $1 / 8$ scaled model (i.e. the $1 / 8$ scaled EDS model). The obtained stacking sequences for each component are shown in Table 6 together with their prototypes. The BCs were maintained consistent between the prototype and the scaled models. The $1 \mathrm{~g}$ static loads applied to the scaled models were appropriately scaled by assuming $\lambda_{p}=1$. The static, modal and buckling behaviour of the prototype wing box model was predicted using the scaled models following the scaling laws described by Eq. (32)-(34).

\subsubsection{Static behaviour}

Fig. 10(a) illustrates the typical wing deflection response, which was obtained using the prototype model under $1 \mathrm{~g}$ static loads as presented in Fig. 9(a). The procedure of predicting the prototype wing deflection using scaled models is demonstrated in Fig. 11. Fig. 11(a) firstly compares the normalised deflection distribution (from the wing root towards the tip) obtained from simulation using models at different scaling levels. Fig. 11(b) then schematically illustrates how the prototype prediction is achieved via extrapolating the results of the scaled model following the scaling laws; scaling in the y and $\mathrm{z}$ directions are governed by $\lambda_{D I M}$ and $\lambda_{D I S P}$ respectively. Subsequently, the prediction results using each scaled model are compared with the prototype results, as displayed in Fig. 11(c). 
(a) 0

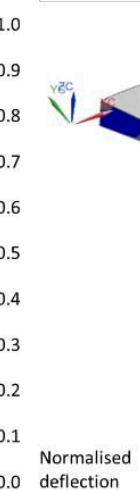

Fig. 10. The normalised distribution of (a) deflection and (b) twist angle of the prototype wing box under $1 \mathrm{~g}$ static loads.

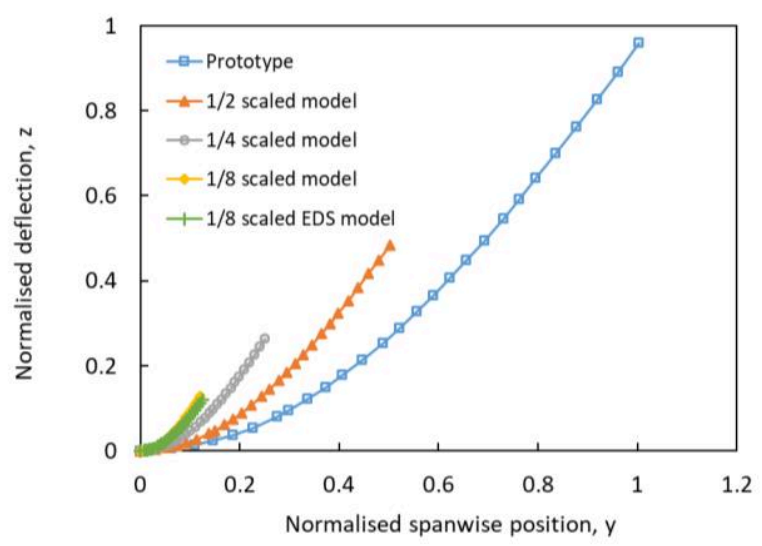

(a)

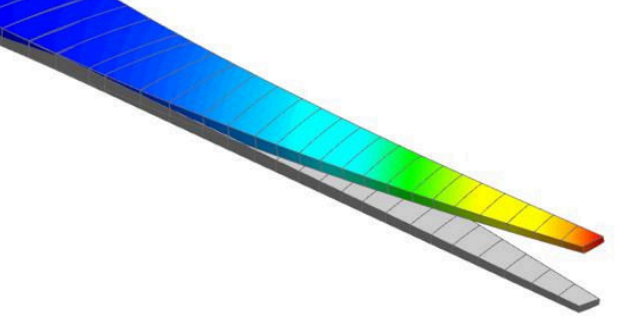

(b)
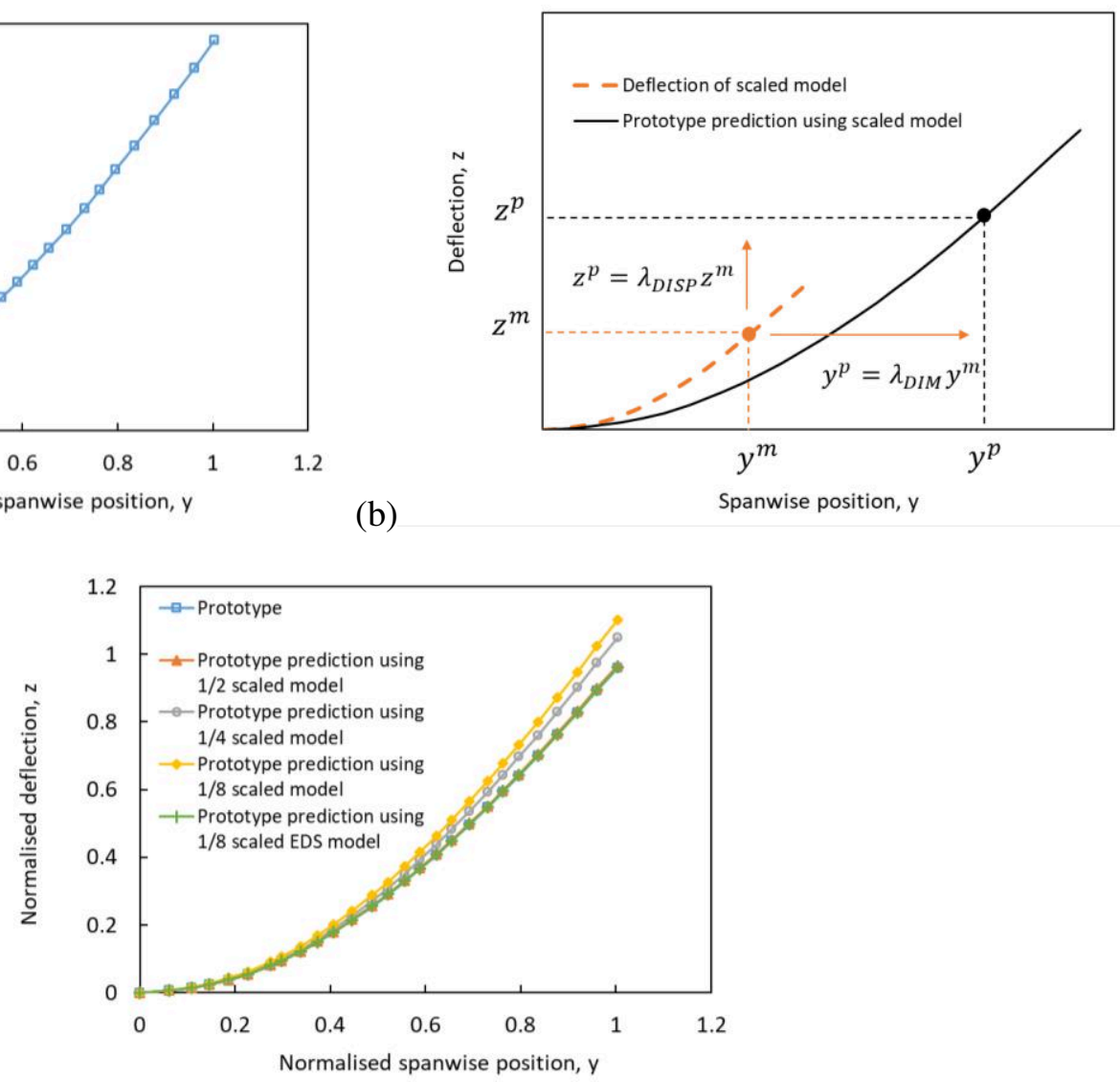

(c)

Fig. 11. (a) Comparison between the simulated wing deflection under $1 \mathrm{~g}$ static loads using models at different scaling levels; (b) schematic illustration of the prediction of prototype deflection using scaled results; (c) comparison between the distribution of prototype wing deflection and the corresponding predictions using the scaled models based on the scaling laws.

In addition, the twist $(\theta)$ of the prototype wing (as illustrated in Fig. 10(b)) was also predicted using the scaled models. Following the concept of dimensional analysis [6], $\lambda_{\theta}=1$ (i.e. $\theta^{m}=\theta^{p}$ ) can be intuitively obtained considering the current similarity conditions when $\lambda_{p}=1$, which acts as supplementary scaling law to Eq. (32)(34). The procedure of predicting the prototype wing twist is similar with that for the prototype wing deflection, as demonstrated in Fig. 12. 

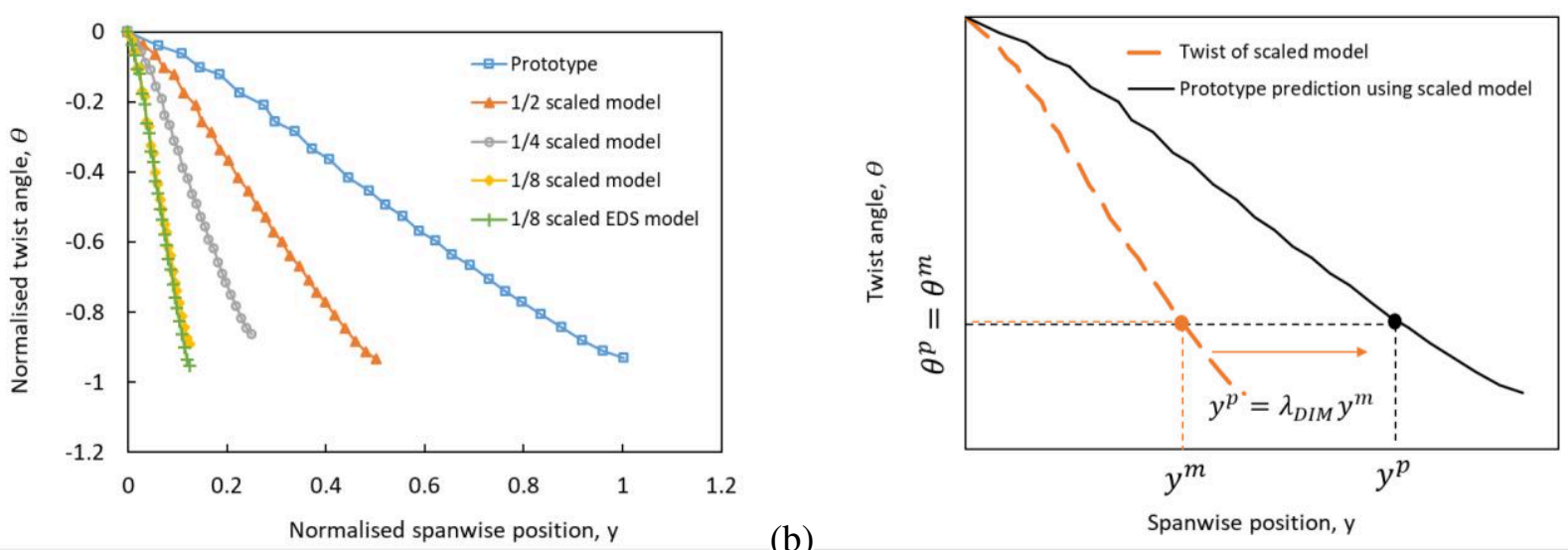

(a)

(b)

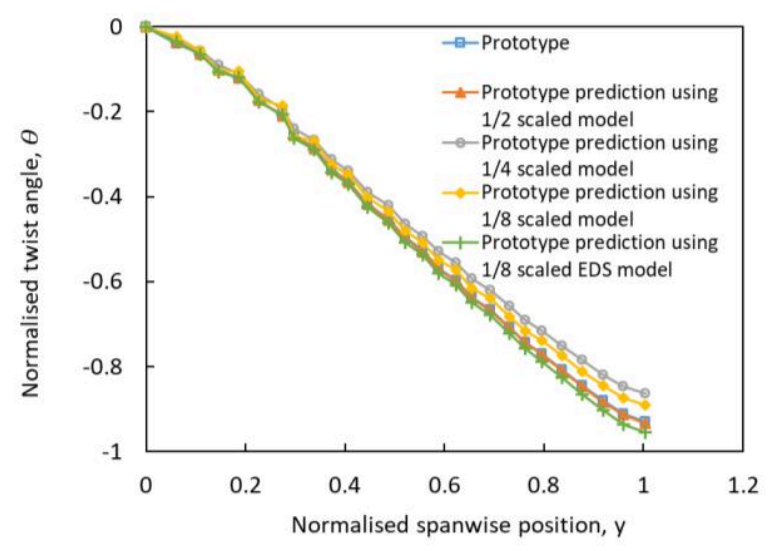

Fig. 12. (a) Comparison between the simulated wing twist under $1 \mathrm{~g}$ static loads using models at different scaling levels; (b) schematic illustration of the prediction of prototype twist using scaled results; (c) comparison between the distribution of prototype wing twist and the corresponding predictions using the scaled models based on the scaling laws.

The prototype prediction errors of both deflection and twist at the wing tip are summarised in Table 7 based on the results shown Fig. 11(c) and Fig. 12(c). It can be seen that the $1 / 2$ scaled model generates the most accurate prediction. The predictions using $1 / 4$ and $1 / 8$ scaled models also present sensible deflection and twist distributions, although the prediction errors increase. Additionally, it is also demonstrated that the accuracy of the prediction using the $1 / 8$ scaled model can be effectively improved if more ply orientation options are applied in designing the stacking sequence of the scaled model. Such enlarged design space promotes the approach of complete similarity.

Table 7. Prediction errors of the deflection and twist (at the wing tip) of the prototype wing box using scaled models.

\begin{tabular}{|l|l|l|l|l|}
\hline \multirow{2}{*}{$\begin{array}{l}\text { Static } \\
\text { behaviour }\end{array}$} & \multicolumn{4}{|c|}{ Prediction errors (\%) } \\
\cline { 2 - 5 } & $\mathbf{1} / \mathbf{2}$ scaled model & $\mathbf{1} / \mathbf{4}$ scaled model & $\mathbf{1} / \mathbf{8}$ scaled model & $\mathbf{1} / \mathbf{8}$ scaled EDS model \\
\hline Deflection & 0.83 & 9.54 & 15.02 & $0.24 \%$ \\
\hline Twist & 0.27 & -7.18 & -4.34 & $2.56 \%$ \\
\hline
\end{tabular}

\subsubsection{Modal behaviour}


In modal analysis of the wing box, $1^{\text {st }}$ bending, sweeping, $2^{\text {nd }}$ bending and torsional modes were selected as the key ones to represent the modal behaviour of the structure [38]. The prototype modal shapes of these four modes are illustrated in Fig. 13. The obtained modal frequencies (normalised) for the prototype and the scaled wing box models are summarised in Table 8 . The errors of the predicted prototype frequencies using the scaling laws are also presented in this table. Generally, good predictions were achieved, particularly when using $1 / 2$ and $1 / 4$ scaled models; most errors remain within $\pm 5 \%$. In addition to modal frequencies, the consistency between the modal shapes obtained using the prototype and the scaled models was also checked in terms of the Modal Assurance Criterion (MAC) value [39]. The associated results are listed in Table 9 , implying a good modal shape consistency in the $1^{\text {st }}$ bending, sweeping and $2^{\text {nd }}$ bending modes between the prototype and the scaled models. However, it becomes less consistent in the torsional mode for the $1 / 4$ and $1 / 8$ scaled models, which is attributed to the limited number of plies as explained in Section 3.1 based on Fig. 7. According to the results for the $1 / 8$ scaled EDS model presented in Table 8 and Table 9 , it is further concluded that the mismatch between model predictions and the prototype can be improved by enlarging the design space, which is consistent with the conclusion made in Section 4.2.1.

(a)

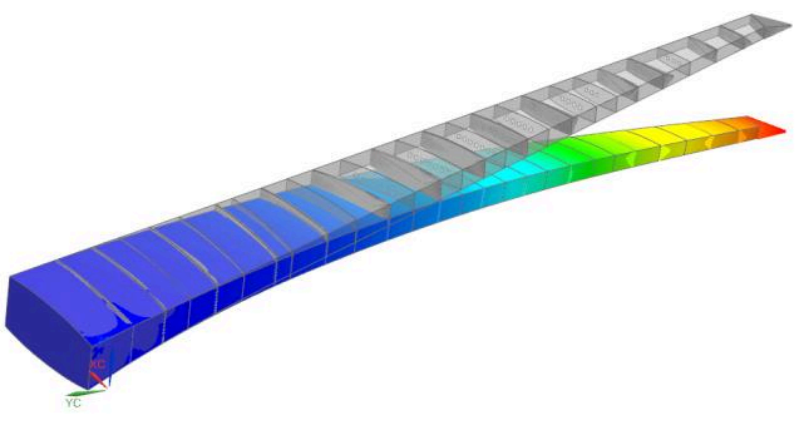

(b)

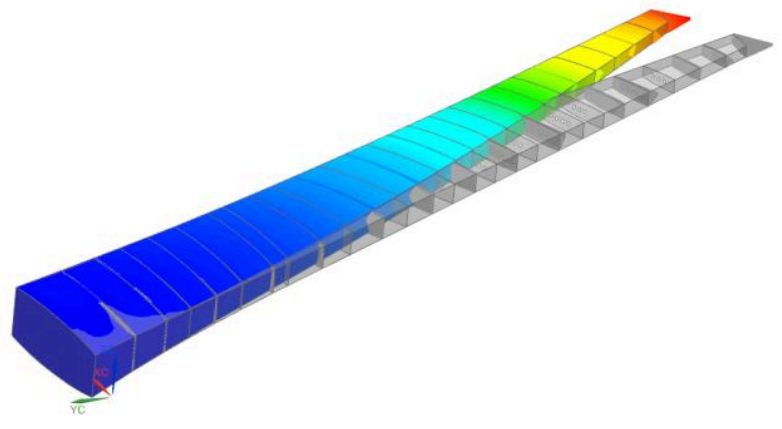

(d)

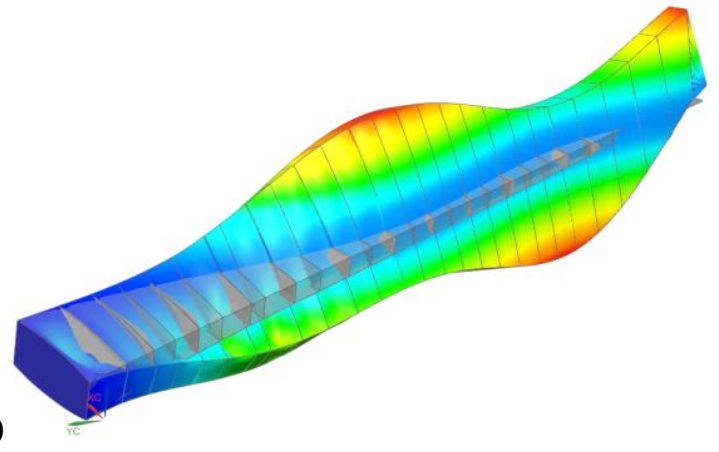

(c)

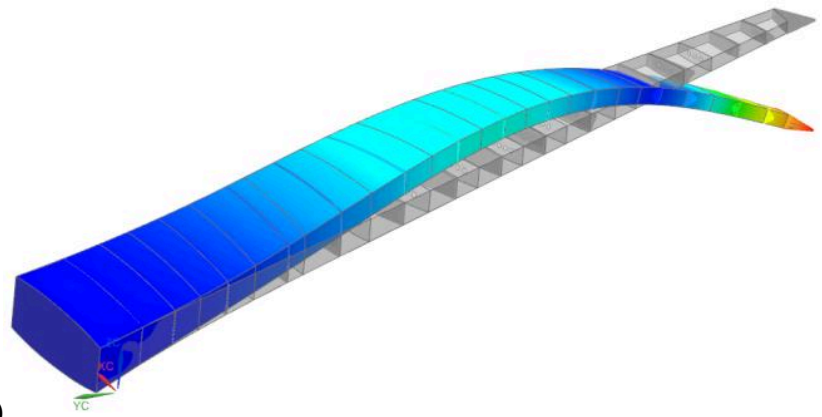

Fig. 13. Key modal shapes of the prototype wing box structure: (a) $1^{\text {st }}$ bending, (b) sweeping, (c) $2^{\text {nd }}$ bending and (d) torsional modes.

Table 8. Normalised frequencies of the key modes of the prototype and the scaled wing box models, with errors (\%) of the corresponding prototype predictions based on the scaling laws.

\begin{tabular}{|l|l|l|l|l|l|l|l|l|l|}
\hline & \multicolumn{4}{|c|}{ FE results (Hz) } & \multicolumn{3}{c|}{ Prediction errors (\%) } \\
\cline { 2 - 8 } Mode & $\begin{array}{l}\text { Prototy } \\
\text { pe }\end{array}$ & $\begin{array}{l}1 / 2 \\
\text { scaled } \\
\text { model }\end{array}$ & $\begin{array}{l}1 / 4 \\
\text { scaled } \\
\text { model }\end{array}$ & $\begin{array}{l}1 / 8 \\
\text { scaled } \\
\text { model }\end{array}$ & $\begin{array}{l}1 / 8 \\
\text { scaled } \\
\text { EDS } \\
\text { model }\end{array}$ & $\begin{array}{l}1 / 2 \\
\text { scaled } \\
\text { model }\end{array}$ & $\begin{array}{l}1 / 4 \\
\text { scaled } \\
\text { model }\end{array}$ & $\begin{array}{l}1 / 8 \\
\text { scaled } \\
\text { model }\end{array}$ & $\begin{array}{l}\text { EDS } \\
\text { scaled } \\
\text { model }\end{array}$ \\
\hline
\end{tabular}




\begin{tabular}{|l|l|l|l|l|l|l|l|l|l|}
\hline $\begin{array}{l}1^{\text {st }} \\
\text { bending }\end{array}$ & $f_{1}$ & $1.990 f_{1}$ & $3.800 f_{1}$ & $7.411 f_{1}$ & $7.987 f_{1}$ & -0.42 & -4.94 & -7.31 & -0.16 \\
\hline $\begin{array}{l}\text { Sweepin } \\
\mathrm{g}\end{array}$ & $f_{2}$ & $1.996 f_{2}$ & $3.870 f_{2}$ & $7.813 f_{2}$ & $8.294 f_{2}$ & -0.19 & -3.26 & -2.34 & 3.68 \\
\hline $\begin{array}{l}2^{\text {nd }} \\
\text { bending }\end{array}$ & $f_{3}$ & $1.997 f_{3}$ & $3.857 f_{3}$ & $7.495 f_{3}$ & $7.969 f_{3}$ & -0.16 & -3.58 & -6.32 & -0.38 \\
\hline Torsional & $f_{4}$ & $2.001 f_{4}$ & $4.354 f_{4}$ & $8.532 f_{4}$ & $7.854 f_{4}$ & 0.03 & 8.84 & 6.65 & -1.83 \\
\hline
\end{tabular}

Table 9. MAC values between the modes obtained using the prototype and the scaled wing box models [39].

\begin{tabular}{|l|l|l|l|l|}
\hline \multirow{2}{*}{ Mode } & \multicolumn{4}{|c|}{ Modal Assurance Criterion (MAC) values } \\
\cline { 2 - 5 } & $1 / 2$ scaled model & $1 / 4$ scaled model & $1 / 8$ scaled model & $\begin{array}{l}1 / 8 \text { scaled EDS } \\
\text { model }\end{array}$ \\
\hline $1^{\text {st }}$ bending & 1.00000 & 0.99999 & 0.99999 & 0.99999 \\
\hline Sweeping & 1.00000 & 0.99999 & 0.99979 & 0.99986 \\
\hline $2^{\text {nd }}$ bending & 0.99998 & 0.99972 & 0.99978 & 0.99982 \\
\hline Torsional & 0.99912 & 0.79199 & 0.84651 & 0.99391 \\
\hline
\end{tabular}

\subsubsection{Buckling behaviour}

Linear buckling behaviour of the prototype wing box was also predicted using the scaled models. Table 10 lists the prediction errors of the prototype critical buckling load, demonstrating a good prediction accuracy. In addition, as shown in Fig. 14, the critical buckling modes obtained using the prototype and the scaled models are also consistent, being located on the top skin near the wing root. It demonstrates the capability of the designed scaled models in accurately predicting the buckling-critical area of the prototype wing.

Table 10. Prediction errors (\%) of the critical buckling load of the prototype wing box using scaled models.

\begin{tabular}{|l|l|l|l|}
\hline \multicolumn{4}{|c|}{ Prediction errors (\%) } \\
\hline $1 / 2$ scaled model & $1 / 4$ scaled model & $1 / 8$ scaled model & $1 / 8$ scaled EDS model \\
\hline 1.01 & -3.55 & 4.04 & -10.85 \\
\hline
\end{tabular}

(a)

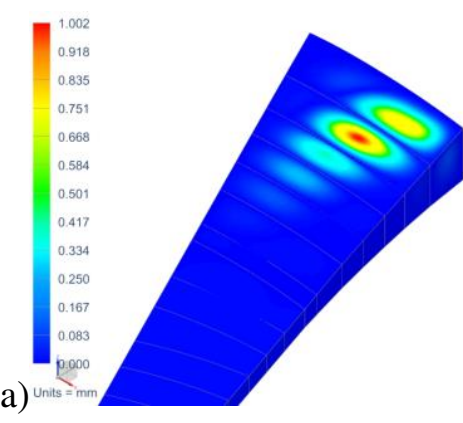

(b)

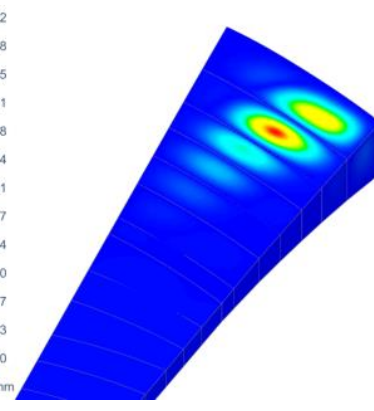

(c)

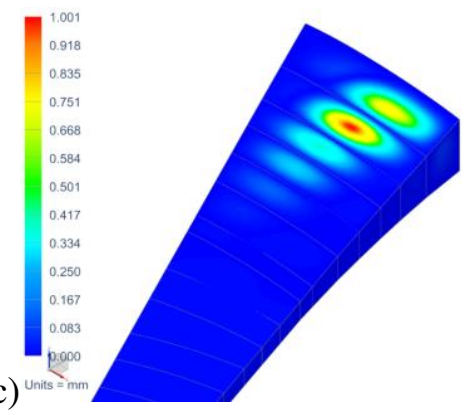




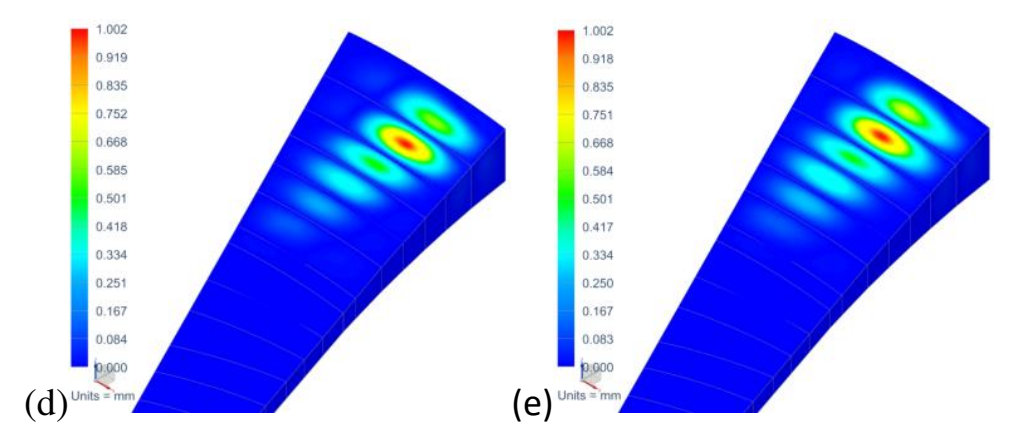

Fig. 14. The critical buckling mode of the (a) prototype, (b) 1/2 scaled, (c) 1/4 scaled, (d) 1/8 scaled and (e) 1/8 scaled EDS wing box models. Note: the models have different dimensions but are zoomed to the same scale for this comparison.

\section{Conclusions}

In this study, generic scaling laws being independent of boundary conditions were firstly derived for plates, beams and stiffened plates, based on the governing equations method. Then a new partial similitude design method based on genetic algorithm (GA) was proposed (referred to as GAPSD) for designing scaled composite laminates when the ply thickness cannot be scaled owing to manufacturing constraints. This new method has been compared with the conventional partial similitude design (CPSD) method by predicting the prototype structural behaviour using scaled models. Its applicability in designing scaled complex structures has also been demonstrated by designing a composite wing box structure. The main conclusions are:

- The proposed GAPSD method has been demonstrated to be advantageous compared with the CPSD method in improving the accuracy of prototype prediction. The average improvement for the investigated laminated plate can be up to $87 \%$. The GAPSD method also enriches the options of the applicable scale factors, being not restricted by the prototype stacking pattern as the CPSD method does.

- Satisfactory prototype predictions of different structural responses, such as the deflection under static bending, modal behaviour, and compressive buckling load, can be realised simultaneously using a single scaled model based on the derived scaling laws.

- By ensuing structural continuity at the interface between adjacent components, the GAPSD method and the associated scaling laws have been demonstrated to be robust for complex structures such as the composite wing box.

- At high scaling levels, the accuracy of prototype predictions may become unstable due to the difficulties in satisfying all the similarity conditions with limited number of plies, which needs cautions during real applications. Satisfactory prediction accuracy can potentially be achieved by enlarging the design space (i.e. allowing more ply orientation options) in the design of scaled models.

\section{Data Availability}

The raw/processed data required to reproduce these findings cannot be shared at this time as the data also forms part of an ongoing study.

\section{References}


1. Wissmann, J., Dynamic Stability of Space Vehicles: Structural Dynamics Model Testing. Vol. 1195. 1968: National Aeronautics and Space Administration.

2. Simitses, G. and Rezaeepazhand, J., Structural similitude for laminated structures. Composites Engineering, 1993. 3(7-8): p. 751-765.

3. Rezaeepazhand, J. and Yazdi, A.A., Similitude requirements and scaling laws for flutter prediction of angle-ply composite plates. Composites Part B: Engineering, 2011. 42(1): p. 51-56.

4. Jackson, K.E., Fasanella, E.L., and Kellas, S., Development of a scale model composite fuselage concept for improved crashworthiness. Journal of Aircraft, 2001. 38(1): p. 95-103.

5. Macagno, E.O., Historico-critical review of dimensional analysis. Journal of the Franklin Institute, 1971. 292(6): p. 391-402.

6. Jha, A., Sedaghati, R., and Bhat, R., Dynamic Testing of Structures Using Scale Models, in 46th AIAA/ASME/ASCE/AHS/ASC Structures, Structural Dynamics and Materials Conference. 2005.

7. Jha, A., Dynamic testing of structures using scale models. 2004, Concordia University.

8. Baker, W.E., Westine, P.S., and Dodge, F.T., Similarity methods in engineering dynamics: theory and practice of scale modeling. 1973: Spartan Books; [distributed by] Hayden Book Co.

9. Coutinho, C.P., Baptista, A.J., and Dias Rodrigues, J., Reduced scale models based on similitude theory: A review up to 2015. Engineering Structures, 2016. 119: p. 81-94.

10. Luo, Z., Zhu, Y.P., Zhao, X.Y., and Wang, D.Y., Determination method of dynamic distorted scaling laws and applicable structure size intervals of a rotating thin-wall short cylindrical shell. Proceedings of the Institution of Mechanical Engineers, Part C: Journal of Mechanical Engineering Science, 2014. 229(5): p. 806-817.

11. Luo, Z., Zhu, Y., Liu, H., and Wang, D., Dynamic Similitude Design Method of the Distorted Model on Variable Thickness Cantilever Plates. Applied Sciences, 2016. 6(8): p. 228.

12. Oshiro, R.E. and Alves, M., Predicting the behaviour of structures under impact loads using geometrically distorted scaled models. Journal of the Mechanics and Physics of Solids, 2012. 60(7): p. 1330-1349.

13. Hilburger, M., Rose, C., and Starnes, J., James. Nonlinear analysis and scaling laws for noncircular composite structures subjected to combined loads. in 19th AIAA Applied Aerodynamics Conference. 2001.

14. Torkamani, S., Navazi, H., Jafari, A., and Bagheri, M., Structural similitude in free vibration of orthogonally stiffened cylindrical shells. Thin-Walled Structures, 2009. 47(11): p. 1316-1330.

15. Wu, J.-J., The complete-similitude scale models for predicting the vibration characteristics of the elastically restrained flat plates subjected to dynamic loads. Journal of Sound Vibration, 2003. 268: p. 1041-1053.

16. Kim, N.-S., Kwak, Y.-H., and Chang, S.-P. Pseudodynamic tests on small-scale steel models using the modified similitude law. in Proceedings of the 13th world conference on earthquake engineering. 2004.

17. Ramu, M., Prabhu Raja, V., and Thyla, P.R., Establishment of structural similitude for elastic models and validation of scaling laws. KSCE Journal of Civil Engineering, 2013. 17(1): p. 139-144.

18. Gronet, M.J., Pinson, E., Voqui, H., Crawley, E., and Everman, M., Preliminary design, analysis, and costing of a dynamic scale model of the NASA space station. 1987.

19. Davis, D., Gronet, M., Tan, M., and Thorne, J., Conceptual design and analysis of a dynamic scale model of the Space Station Freedom. 1994.

20. Rezaeepazhand, J. and Simitses, G., Use of scaled-down models for predicting vibration response of laminated plates. Composite Structures, 1995. 30(4): p. 419-426.

21. Simitses, G. and Rezaeepazhand, J., Structural similitude and scaling laws for buckling of cross-ply laminated plates. Journal of thermoplastic composite materials, 1995. 8(3): p. 240-251.

22. Rezaeepazhand, J. and Simitses, G. Design of scaled down models for predicting shell vibration response. in 36th Structures, Structural Dynamics and Materials Conference. 1996.

23. Rezaeepazhand, J., Simitses, G., and Starnes Jr, J., Scale models for laminated cylindrical shells subjected to axial compression. Composite Structures, 1996. 34(4): p. 371-379. 
24. Ungbhakorn, V. and Singhatanadgid, P., Similitude and physical modeling for buckling and vibration of symmetric cross-ply laminated circular cylindrical shells. Journal of composite materials, 2003. 37(19): p. 1697-1712.

25. Ungbhakorn, V. and Wattanasakulpong, N., Structural similitude and scaling laws of anti-symmetric cross-ply laminated cylindrical shells for buckling and vibration experiments. International Journal of Structural Stability and Dynamics, 2007. 7(04): p. 609-627.

26. Asl, M.E., Niezrecki, C., Sherwood, J., and Avitabile, P., Vibration prediction of thin-walled composite Ibeams using scaled models. Thin-Walled Structures, 2017. 113: p. 151-161.

27. Asl, M.E., Niezrecki, C., Sherwood, J., and Avitabile, P., Similitude analysis of composite I-beams with application to subcomponent testing of wind turbine blades, in Experimental and Applied Mechanics, Volume 4. 2016, Springer. p. 115-126.

28. Coutinho, C.P., Baptista, A.J., and Dias Rodriges, J., Modular approach to structural similitude. International Journal of Mechanical Sciences, 2018. 135: p. 294-312.

29. Krueger, R., Paris, I.L., O'Brien, T.K., and Minguet, P.J., Comparison of 2D finite element modeling assumptions with results from 3D analysis for composite skin-stiffener debonding. Composite Structures, 2002. 57(1-4): p. 161-168.

30. Reddy, J.N., Mechanics of laminated composite plates and shells: theory and analysis. 2004: CRC press.

31. Liu, D. and Toropov, V.V., A lamination parameter-based strategy for solving an integer-continuous problem arising in composite optimization. Computers \& Structures, 2013. 128: p. 170-174.

32. Jing, Z., Chen, J., and Sun, Q., Constrained-manufacturable stacking sequence design optimization using an improved global shared-layer blending method and its 98-line Matlab code. Structural and Multidisciplinary Optimization, 2018. 59(2): p. 539-575.

33. Craddock, J.N. and Yen, S.-C., The bending stiffness of laminated composite material I-beams. Composites Engineering, 1993. 3(11): p. 1025-1038.

34. Matlab Documentation: Mixed Integer Optimization (R2018b). MathWorks.

35. Dayyani, I. and Friswell, M.I., Multi-objective optimization for the geometry of trapezoidal corrugated morphing skins. Structural and Multidisciplinary Optimization, 2016. 55(1): p. 331-345.

36. Morishima, R., Analysis of composite wing structures with a morphing leading edge. 2011, Cranfield University.

37. Hürlimann, F., Kelm, R., Dugas, M., and Kress, G., Investigation of local load introduction methods in aircraft pre-design. Aerospace Science and Technology, 2012. 21(1): p. 31-40.

38. Guo, S., Li, D., and Liu, Y., Multi-objective optimization of a composite wing subject to strength and aeroelastic constraints. Proceedings of the Institution of Mechanical Engineers, Part G: Journal of Aerospace Engineering, 2011. 226(9): p. 1095-1106.

39. Pastor, M., Binda, M., and Harčarik, T., Modal assurance criterion. Procedia Engineering, 2012. 48: $p$. 543-548. 
Structural similitude design for a scaled composite wing box based on optimised stacking sequence

\author{
You, Chao
}

Elsevier

You C, Yasaee M, and Dayyani I. (2019) Structural similitude design for a scaled composite wing box based on optimised stacking sequence. Composite Structures, Volume 226, October 2019, Article number 111255

https://doi.org/10.1016/j.compstruct.2019.111255

Downloaded from Cranfield Library Services E-Repository 